In press, Journal of Personality and Social Psychology

\author{
Insufficiently Complimentary?: Underestimating the Positive Impact \\ of Compliments Creates a Barrier to Expressing Them
}

\author{
Xuan Zhao \\ Stanford University, Department of Psychology \\ Nicholas Epley \\ University of Chicago, Booth School of Business
}

Correspondence author: Xuan Zhao (xuanzhao@stanford.edu)

Author note: We thank Bryan Baird, Yvita Bustos, Alice Fried, Amanda Hopcroft, Anita Joshi, Yena Kim, Jasper Lee, Donald Lyons, Jake Martin, Robyn Myers, John Pezzuto, Ruth Selipsky, Nancy Shrestha, Michelle Wang, Qing Wang, Xueyan Xie, and Zhi Zhang for assistance conducting experiments. We are grateful to James Dungan, Michael Kardas, Nadav Klein, and Amit Kumar for feedback during early stages of this research, and to staff at the Garfield Park Conservatory for coordinating data collection. This research was funded by the Neubauer Family Faculty Fellowship and the University of Chicago Booth School of Business.

All data, materials, and preregistration forms can be accessed via a repository at the Open

Science Framework: https://osf.io/ypk5g/

(c) 2021, American Psychological Association. This paper is not the copy of record and may not exactly replicate the final, authoritative version of the article. Please do not copy or cite without authors' permission. The final article will be available, upon publication, via its DOI: 10.1037/pspa0000277 


\begin{abstract}
Compliments increase the well-being of both expressers and recipients, yet people report in a series of surveys giving fewer compliments than they should give, or would like to give. Nine experiments suggest that a reluctance to express genuine compliments partly stems from underestimating the positive impact that compliments will have on recipients. Participants wrote genuine compliments and then predicted how happy and awkward those compliments would make recipients feel. Expressers consistently underestimated how positive recipients would feel but overestimated how awkward recipients would feel (Experiments 1-3, S4). These miscalibrated expectations are driven partly by perspective gaps in which expressers underestimate how competent — and to a lesser extent how warm — their compliments will be perceived by recipients (Experiments 1-3). Because people's interest in expressing compliments is partly driven by their expectations of the recipient's reaction, undervaluing compliments creates a barrier to expressing them (Supplemental Experiments S2, S3, S4). As a result, directing people to focus on the warmth conveyed by their compliments (Experiment 4) increased interest in expressing them. We believe these findings may reflect a more general tendency for people to underestimate the positive impact of prosocial actions on others, leading people to be less prosocial than would be optimal for both their own and others' well-being.
\end{abstract}

Keywords: social connection, compliments, happiness, well-being, prosocial behavior 


\begin{abstract}
Insufficiently Complimentary?: Underestimating the Positive Impact
of Compliments Creates a Barrier to Expressing Them

"- and I will remark here that the happy phrasing of a compliment is one of the rarest of human gifts and the happy delivery of it another."
\end{abstract}

- Mark Twain (1907), p. 130

Thinking and speaking are guided by different psychological processes (Goldin-Meadow et al., 2008; Pinker, 2007; Slobin, 1996), meaning that Twain was right to distinguish between generating a compliment and delivering it. Thinking well of oneself is also among the more satisfying thoughts a person can have (Baumeister \& Leary, 1995; Diener \& Diener, 1995; DeNeve \& Cooper, 1998; Jones, 1973; Leary, 2007), meaning that Twain was also right to note the happiness that can quickly follow from receiving a nicely-worded compliment (Fea \& Brannon, 2006; Izuma et al., 2008; Swann et al., 1987). However, here we suggest that happily phrased compliments are actually quite common, but their delivery is rarer than would be optimal to maximize both one's own and others' well-being. Specifically, we hypothesize that people systematically underestimate how positively a compliment will be received, which in turn creates a psychological barrier that keeps people from delivering some of the compliments they generate about others. We predict that people would be more interested in expressing the compliments that come to their minds if they accurately understood just how positive their compliments made others feel.

\title{
Insufficiently Complimentary?
}

Giving compliments is an important part of everyday conversation, drawing both strangers and friends closer to each other through the warmth conveyed in kind words (Knapp et al., 1984; Rees-Miller, 2011). Giving compliments is also a readily available way to increase 
both one's own and another person's mood and strengthen a relational bond compared to the effort and expense of other well-documented mood-brightening behaviors such as spending money on others (Izuma et al., 2008; Dunn et al., 2014), writing a gratitude letter (Chaudhry \& Loewenstein, 2019; Kumar \& Epley, 2018; Lambert et al., 2010), or performing random acts of kindness (Curry et al., 2018). A compliment can come to mind almost effortlessly, take only a moment to deliver, come at no financial cost, and be expressed to anyone ranging from a stranger to a spouse. Compliments are likely to be highly valued by recipients because they affirm a recipient's positive self-view (Kwang \& Swann, 2010; Vonk, 2002) and signal warmth and acceptance from another person (Leary \& Baumeister, 2000; Marigold et al., 2007).

These facts raise an important empirical question: Do people express the compliments that come to their minds as often as they should to maximize both their own and others' wellbeing? Anecdotal evidence suggests that people sometimes withhold genuine compliments that they could easily express (e.g., Chapman, 1995). Indeed, a series of four surveys we conducted suggest that withholding compliments might be somewhat widespread even though people recognize that giving more compliments could be desirable. In these surveys $\left(M_{\text {age }}=35.92\right.$, $S D_{\text {age }}=10.96,44 \%$ female, U.S. residents), we asked online participants to rate how often they engaged in a variety of prosocial activities, including expressing compliments to a person they felt close to, or with whom they had a satisfying or dissatisfying relationship $(N=96,97,100$, 193, See Supplemental Materials, Surveys 1-4). Participants reported how often they engaged in each prosocial behavior compared to how often they thought they should, or would like to, on scales ranging from -3 (a lot less often than I think I should [would like to]) to 3 (a lot more often than I think I should [would like to]). Regardless of how often they reported communicating with the target, or how satisfied they were with their relationship, participants consistently 
reported expressing compliments significantly less often than they thought they should ( $p$ s $<.001)$, or would like to $(p=.003)$. This self-assessed deficit was larger for expressing compliments than for other prosocial behaviors, including expressing gratitude, providing emotional support, giving advice, and providing helpful criticism ( $p \mathrm{~s}<.05$; see Survey 1). In a final survey $\left(N=103, M_{\text {age }}=36.52, S D_{\text {age }}=10.58,31 \%\right.$ female; U.S. residents $)$, we asked participants to report how often they expressed versus withheld criticisms to specific close others, as well as how often they expressed versus withheld compliments to the same people. People reported withholding criticisms $62.2 \%$ of the time, on average, but also reported withholding compliments $36.4 \%$ of the time. It is perhaps not surprising that people keep their negative thoughts about others to themselves, but these results suggest that people may be keeping a meaningful number of their positive thoughts to themselves as well.

Is whatever reluctance people feel about expressing a compliment that comes to mind fully warranted?

\section{Miscalibrated Expectations as a Barrier to Prosociality?}

Deliberate choices tend to be guided at least in part by the expected value of an action (Behrens et al., 2009; Bentham, 1825; Decker et al., 2016). As the economist Gary Becker noted in his Nobel Prize address (1993), “The [rational] analysis assumes that individuals maximize welfare as they conceive it," such that, "their behavior is forward-looking." Conceptions of reality, however, are not to be confused with reality itself. Psychologists have documented many ways in which misconceptions of reality can undermine a perfectly rational person's ability to maximize his or her own well-being (Kahneman et al., 1997; Read, 2007; Wilson \& Gilbert, 2005). 
We presume that decisions to express compliments can also be guided by an assessment of expected value. Because a prosocial act is intended to positively impact another person, its expected value is likely to come from its presumed positive impact on the recipient, which subsequently guides people's decisions on interpersonal actions (Crocker et al., 2017). Underestimating the positive impact of expressing compliments that come to mind could therefore serve as a barrier to expressing them more often in everyday life, thereby diminishing the well-being of both expressers and recipients. Some existing research suggests that people may indeed undervalue the positive consequences of connecting with others, such as how much they will enjoy talking with strangers (Epley \& Schroeder, 2014), how positive they will feel spending money on others compared with on themselves (Dunn et al., 2008), how much others will like them after a conversation (Boothby et al., 2018), and how much others will enjoy talking about shared (versus extraordinary but unshared) experiences (Cooney et al., 2014). More closely related to our current hypotheses, one series of recent experiments found that those expressing gratitude tended to underestimate how positive their recipient would feel and overestimate how awkward the recipient would feel, creating a psychological barrier to expressing gratitude in close relationships (Kumar \& Epley, 2018). Like expressing gratitude, giving compliments can also be a prosocial action in which people share positive thoughts with another person, meaning there may exist a similar psychological barrier when people consider giving a compliment. Unlike expressing gratitude, giving compliments is a much broader prosocial act that can focus on any positive attribute of the recipient, while gratitude typically involves giving thanks to another person for some meaningful benefit received by the expresser. Gratitude can therefore communicate evaluations of credit and responsibility (Chaudhry \& Loewenstein, 2019), which simple compliments typically do not. Somewhat surprisingly, while 
expressing gratitude has been commonly presumed to be a prosocial behavior in the literature, giving compliments has typically been studied as a self-interested action meant to enhance one's own image in the eyes of others through strategic self-presentation and ingratiation (e.g., Gordon, 1996; Jones, 1964; Seiter, 2007; Stern \& Westphal, 2010; Vonk, 2001, 2002). Studying compliments allows us to understand whether there is a consistent set of psychological barriers that might inhibit prosociality across a wide range of behaviors, or if the barriers vary across meaningfully different prosocial acts.

One research program developed concurrently with our own suggests that barriers to prosociality might indeed be more widespread. Specifically, Boothby \& Bohns (2021) reported three experiments in which university students were asked to compliment a stranger on campus with either a scripted or unscripted compliment. They found that participants tended to underestimate how positive and overestimate how negative their recipients would feel. Our research extends these results in at least five ways. First, our experiments focus on genuine and meaningful compliments expressed between people in existing relationships, where miscalibration may be somewhat unexpected, rather than between random strangers where compliments were mostly focused on visible physical characteristics (e.g., clothes and accessories). Second, we test the robustness and reliability of our effects using diverse samples of participants recruited primarily from community populations, rather than relying primarily on university samples. Third, we test the impact of receiving compliments against a no-compliment control condition in order to test whether people simply underestimate how positively (and overestimate how negatively) others feel at baseline, or if they misunderstand the impact of compliments, in particular. Fourth, we test a comprehensive explanation in multiple experiments for why people might undervalue compliments, and we compare this account against plausible 
alternative interpretations. Finally, we test in four experiments how people's expectations are related to their interest in actually expressing a compliment, including two experiments testing how calibrating expectations of a recipient's reaction influences people's interest in expressing compliments.

Specifically, we predict that people undervalue the positive impact of compliments on recipients because expressers and recipients evaluate distinct aspects of the same compliment differently in a way that corresponds to their own unique perspective on it. In particular, actors tend to focus on competence when evaluating their own interpersonal actions while observers tend to focus relatively more on the actor's warmth (Abele \& Wojciszke, 2007; Bruk et al., 2018; Fiske et al., 2007; Wojciszke et al., 1998). Those expressing a compliment may therefore be concerned about the specific words or phrases they are using to express their feelings while the recipients are attending more to the prosocial meaning and intent of the feelings being expressed. This could lead expressers to especially underestimate how positively their compliment will be evaluated in terms of its competence, compared to its warmth, consistent with prior research studying expressions of gratitude (Kumar \& Epley, 2018). Because compliments convey a great deal of warmth to the recipient, this difference would lead expressers to underestimate the positive impact (and overestimate the negative impact) of a compliment on their recipients. This perspective gap also predicts that shifting an expresser's attention to the warmth conveyed through their compliment would lead to more calibrated expectations about the recipient's reaction.

In addition, the positive impact of compliments may be easy to undervalue because they are specifically directed to a unique recipient, meaning that the compliments are likely to be uniquely valued by the recipient in a way that is difficult for the expresser, or third-party 
observers, to fully appreciate (Van Boven et al., 2013). This predicts that even third-person observers (who are not receiving an actual compliment directed at them) will also underestimate how warm and competent the compliments will be perceived by recipients, and will therefore also underestimate how positive compliment recipients will feel (c.f., Boothby \& Bohns, 2021). We test this hypothesis in two supplemental experiments (Experiments S1a \& S1b) that we discuss following Experiment 1.

Beyond explaining interpersonal misunderstanding, our theory that mistaken expectations create a barrier to expressing compliments also suggests that the more people expect a compliment will be positively received, the more interested they will be in expressing it. Aligning expressers' expectations with recipients' actual experiences should therefore increase their willingness to express compliments to their potential recipients. Testing this hypothesis is critical for understanding the causal role of miscalibrated expectations in people's interest in expressing versus withholding information in social relationships.

\section{Overview of Experiments}

In a series of nine experiments, we tested our hypotheses that people tend to underestimate the positive impact that compliments will have on recipients (Experiments 1-3), that this miscalibration is guided by a perspective gap in evaluations of competence versus warmth between expressers and recipients (Experiments 1-3, Supplemental Experiments S1a \& S1b), and that people's expectations guide decisions to express or withhold compliments (Experiment 4, Supplemental Experiments S2, S3, S4). We preregistered all experiments except Supplemental Experiment S1b (due to an oversight). We report all methods and measures completely in each experiment, including target sample sizes and whether any data were excluded from analyses. All pre-registered analyses are reported in the Supplemental Materials. 
We note and explain more significant deviations in the primary analyses in the text where appropriate. All experimental materials, data, and preregistration forms can be accessed online: https://osf.io/ypk5g/.

\section{Experiment 1: Miscalibrated Expectations?}

We recruited pairs of people visiting a public park and randomly assigned half to a compliment condition and the other half to a control condition. In the compliment condition, one member of each pair (the expresser) wrote three compliments and then predicted how the other member (the recipient) would feel after reading the compliments, thereby allowing us to test our main hypothesis that expressers would significantly underestimate the positive impact (and overestimate the negative impact) of expressing compliments to another person. One member of each pair in the control condition (the predictor) simply predicted how the other member (the target) would report feeling on a survey, thereby allowing us to test an alternative interpretation that people simply underestimate how positive others feel in general (Ong, Goodman, \& Zaki, 2018). Expressers and recipients in the compliment condition also evaluated their compliments in terms of warmth and competence, to test whether differences in perceptions of these attributes could at least partly explain expressers' systematic misunderstanding of recipients' experiences.

\section{Method}

Participants. We stationed experimenters behind a table with a poster advertising an "Interpersonal Relationship Study" in a public park located in an ethnically diverse neighborhood in a large U.S. city. The experimenters recruited pairs visiting the park together. Participants received a small novelty gift in exchange for their participation. We targeted a sample size of 200 participants (50 pairs per condition) and recruited through the end of our last scheduled shift as we approached that target. A total of 210 participants $\left(M_{\text {age }}=36.84, S D_{\text {age }}=\right.$ 
14.38 range $_{\text {age }}=19-91 ; 62 \%$ female) completed the experiment. One pair did not write three compliments as instructed and was therefore excluded, yielding 52 pairs in each condition.

The experimental survey asked one participant in each pair to report their relationship type and received responses from all but two participants. Our pairs consisted of friends $(N=$ 30), family $(N=10)$, romantic couples $(N=35)$, and married/engaged couples $(N=27)$ who had had known each other for an average of 10.78 years (ranging from 2 weeks to 76 years; $S D=$ 13.79 years).

Procedure. Experiment 1 employed a 2 (condition: compliment vs. control) $\times 2$ (perspective: expected vs. actual) between-participants design. Pairs of participants were randomly assigned to either the compliment condition or the control condition. In the compliment condition, one person was then assigned to be the compliment expresser and the other to be the compliment recipient. In the control condition, one person was assigned to be the predictor and the other to be the target. In both conditions, these roles were referred to only as "Person A" and "Person B" in the materials and instructions.

Compliment condition. The experimenter first gave the expresser a tablet to begin the study in private while instructing the recipient to wait outside the expresser's sight until the expresser completed his/her task. Expressers then read that they were to write down three compliments they could give to their partner, focusing on "positive things you have noticed but have not, for whatever reason, had a chance to compliment your partner on yet," and learned that their partner would later read their compliments before filling out a short survey. Expressers then wrote their three compliments. When finished, expressers predicted how their study partner would report feeling after reading their compliments: how positive/negative their partner would feel, how pleasant their partner would feel, and how awkward their partner would feel. The next 
four items measured expressers' expectations of how their compliments would be perceived by recipients in terms of warmth and competence (based on items from Fiske et al., 2007). Two items measured perceived warmth: "How sincere will your study partner perceive your compliments to be?," and "How warm will your study partner perceive your compliments to be?" Two items measured perceived competence (Kumar \& Epley, 2018): “How articulate will your study partner perceive your compliments to be?," and "To what extent will your partner consider that you were able to provide compliments using words that were 'just right'?" Each item was presented on a separate page with a scale of 0 (not at all) to 10 (extremely), except for the positive/negative item, which had a scale of -5 (much more negative than normal) to 5 (much more positive than normal) with 0 (no different than normal) as the midpoint.

Finally, expressers reported their current relationship quality with the recipients on two bipolar scales, one measuring how close they felt to their partner on a scale ranging from -5 (feels like we're miles apart) to 5 (feels like we're really close), and another measuring how satisfied they were with their relationship on a scale ranging from -5 (extremely dissatisfied) to 5 (extremely satisfied). Expressers then reported how often they gave compliments to, and received compliments from, the recipients on two 7-point scales ranging from -3 (a lot less often than I think I should) to 3 (a lot more often than I think I should), with 0 (exactly as often as I think I should) as the midpoint. Finally, expressers reported how frequently they communicated with each other (from a few times per day to once or twice per month), their gender, and their age.

Once the expresser finished, the experimenter retrieved the recipient who was then seated in private and shown their expresser's three compliments on a tablet. Recipients then provided responses on all of the same items predicted by the expresser but rephrased for the recipient's 
perspective. Finally, they responded to the same additional survey items described above, and described their relationship type and relationship length with the expresser.

Once the recipient finished, each pair was reunited, debriefed, thanked, and dismissed.

Control condition. The control condition procedure was similar to the compliment condition except that no compliments were exchanged, and hence one person (the predictor) in each pair was simply predicting how the other person (the target) would report feeling at that moment. Because predictors in the control condition did not give any compliments, they also did not answer the four items evaluating their compliments in terms of perceived warmth and competence.

\section{Results}

Positive Mood. To test whether expressers underestimated the positive impact of their compliments, we first created a composite score of expected and actual positive mood by adding 5 to the negative/positive mood item and then averaged it together with the pleasantness item $\left(r_{\text {expected }}=.65 ; r_{\text {actual }}=.62 ; p \mathrm{~s}<.001\right) .{ }^{1}$ A 2 (condition: compliment, control) $\times 2$ (perspective: expected vs. actual) repeated measures ANOVA with perspective as a repeated measure yielded a significant main effect of condition, $F(1,102)=7.11, p=.009, \eta^{2}{ }_{p}=.065$, and perspective, $F(1,102)=12.67, p<.001, \eta_{p}^{2}=.11$, qualified by a marginally significant interaction between condition and perspective, $F(1,102)=3.64, p=.059, \eta_{p}^{2}=.034 .^{2}$ As predicted, compliment

\footnotetext{
${ }^{1}$ Before conducting Experiment 1, we preregistered combining pleasantness and awkwardness into a composite index, but results of this and all subsequent experiments indicated that pleasantness was strongly correlated with positive mood, but was not meaningfully correlated with awkwardness (e.g., Experiment 1: $\left.r_{\text {expresser }}=-.08, p=.43 ; r_{\text {recipient }}=-.24, p=.015\right)$. We therefore report the positive mood composite including pleasantness and analyzed awkwardness separately for all experiments. We preregistered this analysis plan in subsequent experiments once this consistent pattern became clear to us.

2 Fitting a linear mixed model with condition and perspective as fixed effects and participant pairs as random effects yielded the same conclusions as the pre-registered repeated measures ANOVA we report here. Subsequent experiments preregistered linear mixed models for these analyses, but we report the simpler ANOVA results throughout the main text for ease of presentation and because they yield the same conclusions.
} 
expressers significantly underestimated how positive their recipients would feel $(M s=7.79$ vs. 8.81 , respectively), $F(1,51)=20.19, p<.001$, but predictors in the control condition did not underestimate how positive their target would feel $(M s=7.50$ vs. 7.81 , respectively), $F(1,51)=$ $1.08, p=.30$ (see Figure 1A). This pattern suggests people do not simply underestimate others' mood in general, as might be expected if predictions of others' experiences were simply regressive (Moore \& Healy, 2008), but that people instead underestimate others' positive response to receiving compliments, in particular. Indeed, expressers did not expect their recipients to feel more positive than predictors expected their targets in the control condition to feel, $F(1,102)=.80, p=.37$, even though reading compliments indeed made recipients feel significantly more positive than targets in the control condition, $F(1,102)=12.18, p=.001$.

(A)

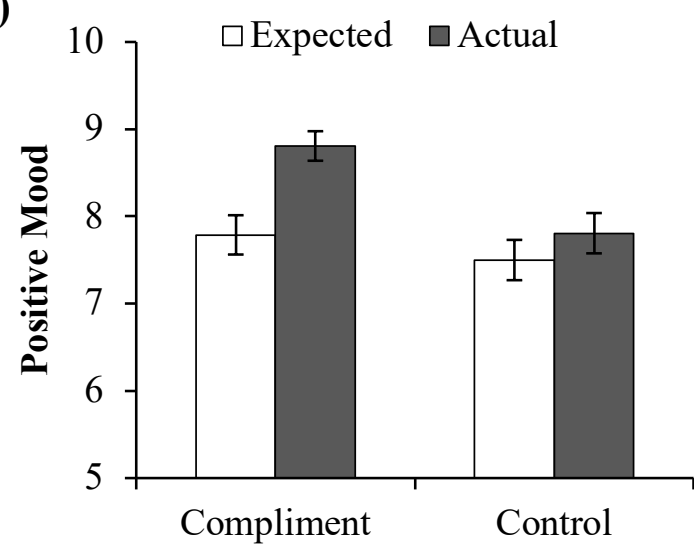

(B)

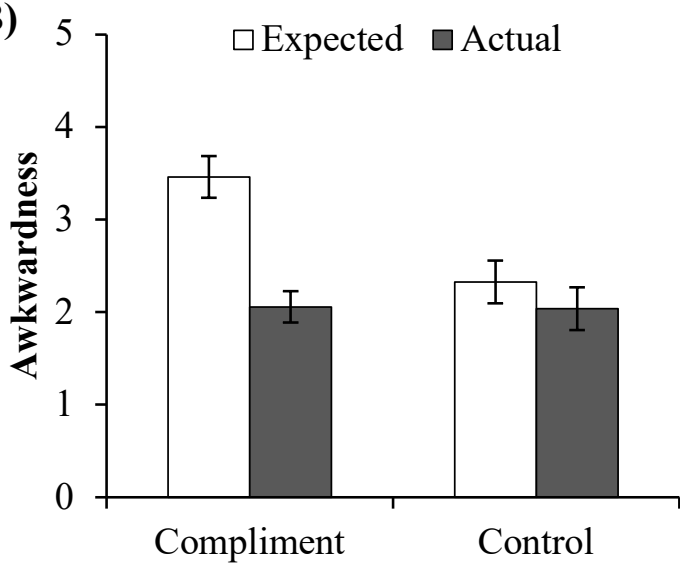

Figure 1. Expected and actual positive mood (Panel A) and awkwardness (Panel B) in the compliment and control conditions in Experiment 1. Error bars reflect \pm 1 standard errors.

Awkwardness. To test whether expressers also overestimate a potential negative cost of expressing compliments, we conducted the same analysis on evaluations of awkwardness. This yielded a significant main effect of perspective, $F(1,102)=8.00, p=.006, \eta^{2}{ }_{p}=.073$, qualified 
by a marginally significant interaction, $F(1,102)=3.48, p=.065, \eta^{2} p=.033$. As predicted, expressers overestimated how awkward their recipient would feel $(M \mathrm{~s}=3.46$ vs. 2.06 , respectively), $F(1,51)=8.97, p=.004$, but predictors in the control condition $\operatorname{did}$ not $(M s=2.33$ vs. 2.04, respectively), $F(1,51)=.60, p=.44$ (see Figure 1B). Expressers expected that their compliments would make their recipients feel more awkward than predictors expected their targets to feel, $F(1,102)=4.71, p=.032$. In reality, reading compliments did not make recipients feel any more awkward than targets in the control condition, $F(1,102)=.002, p=.97$.

Warmth and competence. Finally, to test whether miscalibrated expectations of recipients' reactions could stem from differences in evaluations of competence versus warmth of the compliments, we averaged the two warmth items $(r=.51, p<.001)$ and two competence items $(r=.69, p<.001)$ to create composites for both expressers and recipients. A 2 (attribute: warmth vs. competence) $\times 2$ (perspective: expresser vs. recipient) repeated measures ANOVA revealed a significant main effect for attribute, $F(1,51)=79.89, p<.001, \eta^{2}{ }_{p}=.61$, and a significant main effect of perspective, $F(1,51)=44.66, p<.001, \eta^{2}{ }_{p}=.47$, qualified by a significant interaction, $F(1,51)=11.18, p=.002, \eta^{2} p=.18$. As shown in Figure 2, expressers underestimated the perceived competence of their compliments (expresser: $M=6.62, S D=1.55$; recipient: $\left.M=8.59, S D=1.70 ; F(1,51)=42.44, p<.001, \eta^{2}{ }^{2}=.45\right)$ more than their perceived warmth (expresser: $M=8.12, S D=1.35$; recipient: $M=9.16, S D=1.17 ; F(1,51)=22.36, p$ $<.001, \eta_{p}^{2}=.30$ ). These results are consistent with prior research on more lengthy and detailed expressions of gratitude (Kumar \& Epley, 2018), and the competence result is consistent with concurrently conducted research investigating compliments to strangers (Boothby \& Bohns, 2021). This suggests a potentially robust tendency for those who express kind thoughts to be 
overly self-critical about how well they are expressing their feelings by getting the words "just right" when anticipating how positive their compliments might make another person feel.

Indeed, expressers' expectations of how warm and how competent their compliments would be perceived to be were strongly correlated with their expectations on how positive their recipient would feel $(r \mathrm{~s}=.62$ and $.57, p \mathrm{~s}<.001)$. Recipients' evaluations of warmth and competence were strongly correlated with their positive mood as well $(r \mathrm{~s}=.76$ and $.62, p \mathrm{~s}$ $<.001)$. Interestingly, awkwardness was not correlated with either the perceived warmth or competence conveyed in the compliment from either perspective, perhaps suggesting that both expected and experienced awkwardness come more from the delivery of a compliment rather than from attributes conveyed by the compliment itself $(p s>.18)$.

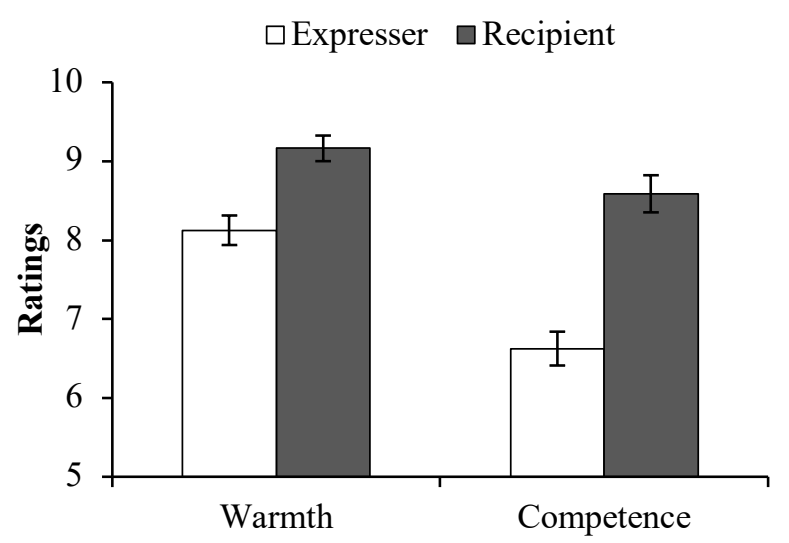

Figure 2. Expected (i.e., expresser) and actual (i.e., recipient) ratings of how warm and competent the compliments were perceived to be in Experiment 1. Error bars reflect \pm 1 standard errors.

Mediation analysis. An exploratory mediation analysis suggests that miscalibrated expectations of competence and warmth could account for a statistically significant proportion of variance in the discrepancy between expressers' expected and recipients' reported positive 
mood. Because expressers and recipients were nested in pairs, we employed a within-subjects mediation analysis using MEMORE macro in SPSS (Montoya \& Hayes, 2017) and performed a 5,000 resampling bootstrap with warmth and competence as simultaneous mediators. As shown in Figure 3, expressers underestimated how warm and how competent their compliments would be perceived by their own recipient ( $b s=1.96$ and 1.04 , respectively, $p s<.001$ ), both of which were significantly correlated with their underestimation of their recipient's positive mood (competence: $b=.36, p<.001$; warmth: $b=.36, p=.004$ ). Although competence yielded a directly larger mediation effect than warmth $(.71$ and $.38,95 \% \mathrm{CIs}=[.24,1.19]$ and $[0, .99]$, respectively), these effect sizes did not differ significantly from each other $(95 \% \mathrm{CI}=[-1.09$, $.62])$.

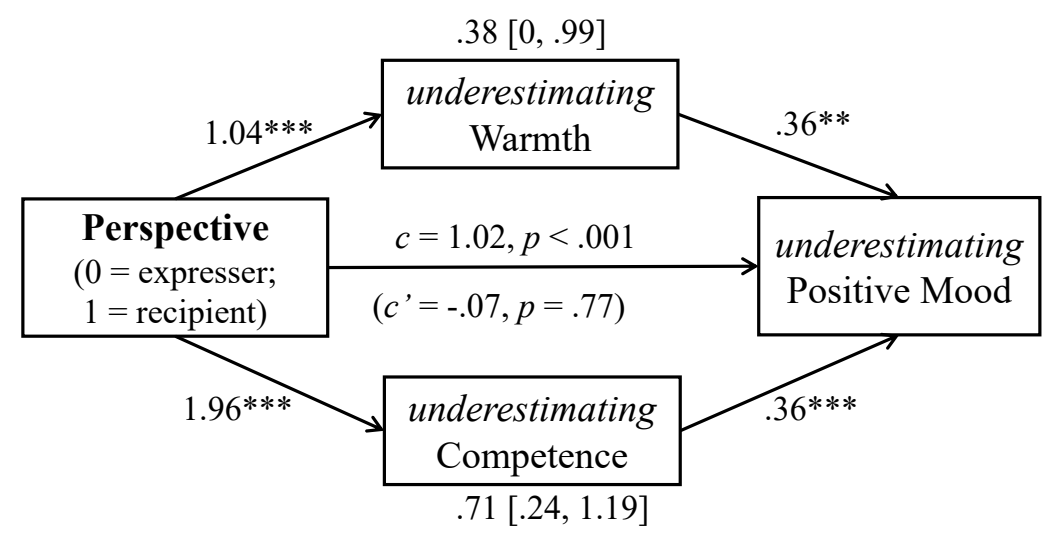

Figure 3. Mediational analysis testing the relationship between miscalibrated expectations of perceived competence and warmth of the compliments and miscalibrated expectations of recipients' positive moods in Experiment 1.

Compliment frequency. Replicating results in the introductory surveys, participants again reported giving compliments less often than they thought they should $(M=-.76, S D=$ $1.34), t(207)=-8.23, \mathrm{p}<.001, d=.57$ (see Supplemental Materials). 


\section{Third-party observers}

Because compliments are kind words specifically directed to a recipient, they are likely to be perceived as uniquely warm and competent from the recipient's perspective. If so, then not only would those expressing compliments underestimate those compliments' value to recipients, but so would third-party observers who simply read the compliments and anticipated how an actual recipient would feel. We tested this hypothesis in two additional experiments whose details are described in full in the Supplemental Materials (Experiments S1a and S1b).

Specifically, we recruited new participants from the same location and at the same time of day as in Experiment 1 and yoked them to pairs from Experiment 1.. These observers read the three compliments written by their yoked expresser and predicted the recipient's reactions either from their own perspective (Experiment S1a), or after imagining themselves as the expresser or the recipient (Experiment S1b). Results indicated that third-party observers in both experiments, regardless of the perspective they were asked to take, underestimated how positive the actual recipients would feel to the same degree as the actual expressers. Third-party observers also underestimated how competent and how warm the compliments would be perceived. Exploratory mediation analysis further showed that underestimating the perceived warmth of those compliments - but not the perceived competence - significantly mediated observers' tendency to underestimate recipients' positive experience.

Interestingly, these results among third-party observers differ from those recently reported by Boothby \& Bohns (2021, Study 4), where participants who imagined someone else receiving a compliment from a stranger (e.g., "I like your shirt") anticipated the recipient to feeling just as positive, on average, as the actual recipients and were thus more calibrated than the compliment expressers. We note, however, that their experiment differed from ours in at 
least two important ways: First, while third-party observers can easily appreciate a generic compliment on a stranger's appearance, meaningful compliments between close friends or family members are likely more contextual and are grounded in shared memories, making the interpersonal warmth less accessible to outsiders. Second, observers in their experiment did not have access to the exact compliments shared by expressers. Instead, these hypothetical observers considered the abstract notion of giving a compliment without focusing on the precise compliment expressed. Our participants, in contrast, evaluated the exact compliments shared by expressers, and hence were able to evaluate the precise words of the compliments. The discrepancy between our findings and that of Boothby \& Bohns (2021) is also consistent with our proposed mechanism of differing focus of competence and warmth between compliment expressers and recipients (see Experiments 3 and 4).

\section{Experiment 2: Alternative Interpretations}

Companions who have known each other for an average of 10 years surely understand a great deal about each other, but the results from Experiment 1 indicate that they do not fully understand the impact that their kind words will have on each other. Those who expressed three compliments undervalued the positive impact that their words would have on their recipient, significantly underestimating recipients' positive mood and overestimating recipients' feelings of awkwardness. This misunderstanding was unique to expectations about compliments as participants in the control condition — who did not exchange compliments- did not systematically misunderstand their partners' positive mood or feelings of awkwardness. As a result, significant miscalibration emerged in expectations of others' reactions to a compliment, rather than from simply making overly regressive predictions of others' emotional experiences. 
Nevertheless, there are three alternative interpretations of these results, which we designed Experiment 2 to test directly. First, our procedure of giving three compliments to another person all at once is potentially unusual, and hence not representative of what might be a more typical experience of giving a single compliment to another person. We therefore asked compliment expressers in Experiment 2 to write either one or three compliments to their recipient to test if this meaningfully affects expressers' expectations or recipients' experiences. Second, another perspective gap that could create miscalibrated expectations between expressers and recipients is a "curse of knowledge" (Camerer, Loewenstein, \& Weber, 1989). That is, because expressers know of the praiseworthy qualities in their partner that deserve a compliment, they may assume their kind words are equally known to their recipient, and hence obvious and unsurprising. Prior research on gratitude (Kumar \& Epley, 2018) found that those expressing gratitude significantly underestimated how surprised recipients would be in receiving their letter of gratitude and how surprised they would be by its content, but also found that these judgments were not related to interest in expressing gratitude. We tested this potential curse of knowledge mechanism in Experiment 2 by examining whether compliment expressers underestimate how surprised recipients would be by their compliment(s). Finally, compliment expressers may worry that sharing kind words with another person could disrupt the status equilibrium in their relationship, making the expressers seem relatively weak or submissive. People may expect that expressing a compliment could lower their perceived status in the eyes of a recipient due to social comparison (Sezer, Brooks, \& Norton, 2020), or it could appear to raise the status of the recipient and potentially be perceived as disingenuous or ingratiating (Vonk, 1998, 1999; Westphal \& Stern, 2007). We assessed this possibility by measuring how relatively weak and 
submissive versus strong and dominant expressers expected their compliment-giving behavior to be perceived, and compared that against recipients' actual evaluations.

Finally, both compliment expressers and recipients reported their mood before and after giving or receiving compliments, thereby allowing us to assess the relative causal impact of both giving and receiving compliments on people's moods. People tend to feel happier when performing prosocial actions. One experiment indicated that people who give a stranger a compliment also report being in a more positive mood after doing so (Boothby \& Bohns, 2021), indicating that any barriers to expressing compliments could also cause people to miss opportunities to increase their own well-being. Experiment 2 allows us to test which experience creates the most positive mood: giving compliments or receiving compliments.

\section{Method}

Participants. We aimed to collect 50 acquainted pairs per condition after exclusions. Due to social distancing policies stemming from COVID-19, we conducted this experiment online and advertised via the Internet to potential participants in our research center's subject pool of students and community members recruited from the local area as well as from across the United States. All participants who signed up for this experiment were assigned to the role of expresser and provided the contact information of the recipients who would receive their compliments. Because this experimental design yields imperfect response rates from recipients (see also Kumar \& Epley, 2018), we continued collecting data from expressers beyond our targeted number until we had responses from at least 50 recipients in each condition. Expressers spent approximately 10 minutes, on average, on their task and received a \$3 Amazon gift card in exchange for their participation. Recipients spent 2 to 3 minutes, on average, to complete their survey and did not receive financial compensation. 
A total of 138 people participated as expressers $\left(M_{\text {age }}=29.69, S D_{\text {age }}=12.58\right.$; range $_{\text {age }}=$ $19-68 ; 68.8 \%$ female), and 112 recipients responded to our survey (an $81 \%$ response rate; $M_{\text {age }}=$ 31.92, $S D_{\text {age }}=13.71 ;$ range $_{\text {age }}=18-74 ; 62.0 \%$ female $)^{3}$. We excluded one pair from all analyses because the expresser did not write a compliment. We excluded two more pairs from the following analyses where recipients reported unusually negative moods both before $(-2.45$ and 2.92 SDs below the mean) and after receiving their compliments (both $-4.37 S D$ s below the mean), which made them statistical outliers ${ }^{4}$. This yielded 109 pairs in the final analyses. These pairs consisted of friends $(N=48)$, family $(N=31)$, married/engaged couples $(N=20)$, romantic couples $(N=9)$, and colleagues $(N=1)$. The expressers reported knowing their recipient for an average of 13.42 years (ranging from eight months to 45 years; $S D=10.81$ years).

Procedure. This experiment employed a 2 (perspective: expresser vs. recipient) $\times 2$ (compliment number: one vs. three) between-participants design. We first asked expressers to identify someone they could compliment in their life and then briefly described their relationship type and how long they had known their recipient. Participants then reported their own mood by responding to the item, "How positive/negative do you feel right now?," using the same scale as in Experiment 1.

\footnotetext{
${ }^{3}$ We also collected demographic information on participants' racial/ethnic background and highest level of education. Participants ranged across racial/ethnic groups (34\% Asian, 14\% Black, 10\% Hispanic, 31\% White, 4\% multiracial or other, $7 \%$ did not respond) and had various amounts of educational experience ( $40 \%$ bachelor's degree, $30 \%$ part of college, $19 \%$ post-graduate degrees, $7 \%$ high school, and $4 \%$ less than high school or did not report).

${ }^{4}$ We did not think to include the standard practice of excluding statistical outliers more than 3SDs from the mean in our preregistration as we had not observed them in other experiments in this project. In retrospect, recipients' unusually negative mood in those two instances — even before receiving the compliment - might be related to a procedural change as we attempted to recruit online during COVID-19. In all other experiments, we recruited participant pairs simultaneously at a time that was convenient for both participants, whereas expressers in this experiment volunteered their recipient's email as they completed their portion and we later reached out to the nominated recipients to recruit them. Importantly, including these two pairs in all analyses does not change any primary findings (see Footnote 5 for an example).
} 
Expressers then read the same compliment-writing prompt as in Experiment 1, adjusted to ask participants to write either one compliment or three compliments. Expressers then reported their mood again on the same scale as above, followed by the same warmth-related and competence-related items as in Experiment 1. To test the potential role of a "curse-ofknowledge" in explaining miscalibrated expectations, expressers then reported the extent to which they expected their recipient to report "already being aware that you thought this way about him/her" and "being surprised by the content of your compliment" on scales from 0 (not at all) to 10 (extremely). To test expressers' beliefs about the impact of giving compliments on their perceived power and status in the relationship, expressers indicated the extent to which their compliment-giving behavior would make them appear relatively strong and dominant or relatively weak and submissive to their recipient, on a scale ranging from -5 (very week and submissive) to 5 (very strong and dominant) with 0 (neither submissive nor dominant) as the midpoint. Finally, expressers reported gender, age, race/ethnicity, and the highest education level.

We emailed recipients on the following day and informed them that they were given a compliment by their expresser (with name specified) in our study. After consenting to participate, recipients reported their current mood on the same scale used by expressers. Recipients then read their compliment(s) and reported how positive and how awkward they felt, how warm and competent they perceived the compliment(s) to be, how surprised they were by the compliment(s), and how strong or weak they perceived their expresser's compliment-giving behavior to be on the same scales that expressers used. Finally, recipients responded to the same demographic questions as above.

\section{Results}


Positive mood. Following our pre-registered analysis plan, we created a composite measure of positive mood after confirming the strong correlation between the negative/positive mood and the pleasantness item $\left(r_{\text {expresser }}=.67 ; r_{\text {recipient }}=.73 ; p \mathrm{~s}<.001\right)$ and then conducted a linear mixed model regression with perspective (expresser vs. recipient) and compliment number (one vs. three) as fixed effects and participant pairs as random effects. Results indicated a significant main effect of perspective, $F(1,107)=10.16, p=.002, \eta^{2}{ }^{2}=.086$, a marginally significant main effect of compliment number, $F(1,107)=3.44, p=.066, \eta^{2} p=.031$, and a nonsignificant perspective by compliment number interaction, $F(1,107)=0.17, p=.68, \eta_{p}^{2}=$ .001. Replicating Experiment 1, expressers significantly underestimated how positive their recipients would feel (expresser: $M=7.49, S D=1.40$; recipient: $M=8.04, S D=1.50$ ), regardless of whether they were giving one compliment or three compliments ${ }^{5}$.

Awkwardness. The same linear mixed model regression on awkwardness indicated only a significant main effect of perspective, $F(1,107)=25.86, p<.006, \eta^{2}{ }_{p}=.20$, with expressers significantly overestimating how awkward their recipients would feel (expresser: $M=3.04, S D=$ 2.78; recipient: $M=1.54, S D=2.14$ ) regardless of whether they were giving one or three compliments to recipients.

Warmth and competence. As in Experiment 1, we averaged the two warmth items ( $r$ $=.78, p<.001)$ and the two competence items $(r=.75, p<.001)$ to create composite scores for each attribute and subjected them to a 2 (perspective: expresser vs. recipient) $\times 2$ (compliment number: one vs. three) $\times 2$ (attribute: warmth vs. competence) linear mixed model regression with a random intercept for each pair, a random intercept for perspective within each pair, and a

\footnotetext{
${ }^{5}$ Including the two pairs where recipients reported unusually negative mood throughout the study yielded a significant main effect of perspective, $F(1,109)=5.59, p=.020, \eta^{2}{ }^{2}=.049$, but neither a significant main effect of compliment number, $F(1,109)=1.81, p=.18, \eta^{2}{ }^{2}=.016$, nor any interaction, $F(1,109)=0.84, p=.36, \eta^{2}{ }_{p}=.008$.
} 
random intercept for attribute within each pair. Replicating Experiment 1, this analysis yielded a significant main effect for perspective, $F(1,107)=62.08, p<.001, \eta^{2}{ }_{p}=.37$, and a significant main effect of attribute, $F(1,107)=48.21, p<.001, \eta^{2}{ }_{p}=.31$, qualified by a significant perspective $\times$ attribute interaction, $F(1,107)=23.34, p<.001, \eta^{2}{ }^{2}=.18$ (all other effects were nonsignificant, $p \mathrm{~s}>.66$ ). Compliment expressers underestimated the perceived warmth of their compliments (expresser: $M=7.76, S D=1.78$; recipient: $M=8.85, S D=1.50 ; F(1,107)=33.26$, $\left.p<.001, \eta^{2}{ }_{p}=.30\right)$, but underestimated the perceived competence of their compliments to a significantly larger extent (expresser: $M=6.73, S D=2.12$; recipient: $M=8.58, S D=1.49$; $\left.F(1,107)=74.42, p<.001, \eta^{2} p=.45\right)$.

Consistent with Experiment 1, expressers' expectations about the perceived warmth and competence of their compliments were significantly correlated with their expectations of their recipients' positive mood $(r \mathrm{~s}=.53$ and $.52, p \mathrm{~s}<.001)$. Recipients' evaluations of the warmth and competence of the expressers' compliments were correlated with their positive mood as well $(r \mathrm{~s}=.44$ and.43, $p \mathrm{~s}<.001)$. Unlike in Experiment 1, warmth and competence evaluations were negatively correlated with awkwardness from both the expressers' perspective $(r \mathrm{~s}=-.32$ and $-.16, p \mathrm{~s}<.001$ and $=.089)$ and the recipients' perspective $(r \mathrm{~s}=-.37$ and $-.36, p \mathrm{~s}<.001)$.

Mediation analysis. As shown in Figure 4, an exploratory mediation analysis following the same procedure used in Experiment 1 indicated that underestimating how competent one's compliment(s) was/were perceived accounted for a significant proportion of the variance in expressers' underestimation of their recipient's positive mood. Unlike in Experiment 1, the indirect effect of underestimating warmth was nonsignificant when entered as a simultaneous mediator with underestimating competence, likely because it was overshadowed by the larger indirect effect of the competence path (see more details in Supplemental Materials). 


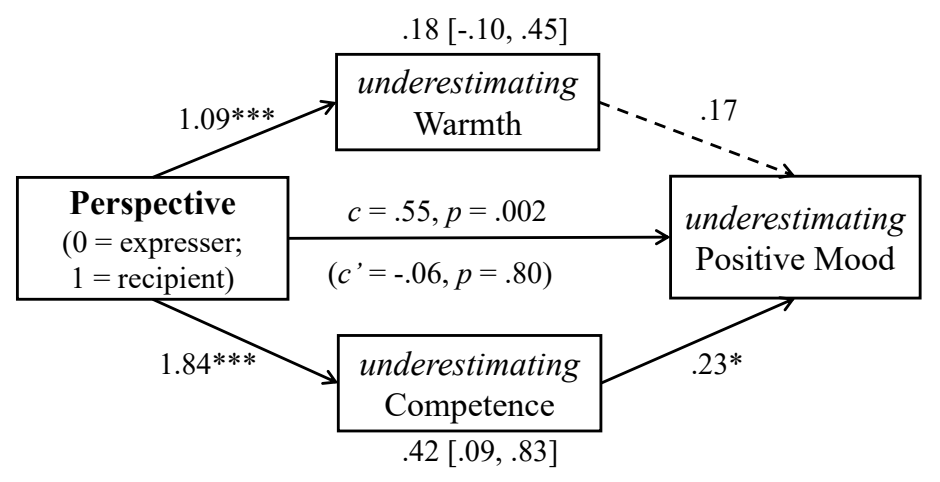

Figure 4. Mediational analysis testing the relationship between miscalibrated expectations of perceived competence and warmth of the compliments and miscalibrated expectations of recipients' positive moods in Experiment 2.

Surprise. To assess whether expressers misunderstood the extent to which their compliments were already known to their recipient, we first calculated composite scores of surprise from the two items $\left(r_{\text {expresser }}=.44 ; r_{\text {recipient }}=.41 ; p \mathrm{~s}<.001 ;\right.$ the "already aware" item was reverse-coded $)^{6}$ and then analyzed them in a linear mixed model regression. We observed nonsignificant effects of perspective, compliment number, and their interaction, $p \mathrm{~s}>.41$, indicating that expressers did not underestimate how surprised their recipients would be (expresser: $M=6.12, S D=2.08$; recipient: $M=6.17, S D=2.29$ ). Additional exploratory analyses revealed a small and marginally significant correlation between expected surprise and positive mood for expressers $(r=.16, p=.098)$, and a nonsignificant correlation between surprise and positive mood for recipients $(r=.08, p=.40)$. Similar to results reported with

\footnotetext{
${ }^{6}$ We preregistered our intention to calculate a composite score of surprise upon confirming that the two items were highly correlated (i.e., $r>=.50$ ). Given that they were only moderately correlated, we performed the same statistical analysis on each item separately and found no significant effects for either the first item $(p \mathrm{~s}>.58)$ or the second item, $p \mathrm{~s}>.14$. Due to the lack of meaningful differences, we reported composite scores here for brevity.
} 
expressions of gratitude (Kumar \& Epley, 2018), a "curse of knowledge" does not seem to explain why expressers undervalue the positive impact of expressing compliments.

Relative status. To assess the potential impact of giving compliments on perceptions of strength versus weakness, and hence relative status in a relationship, we analyzed participants' ratings on this item in the same linear mixed model as above. Results indicated only a significant main effect of perspective, $F(1,107)=10.43, p=.002, \eta^{2}{ }_{p}=.090$, indicating that expressers underestimated how strong and dominant the recipients would perceive their compliment-giving to be (expresser: $M=0.67, S D=1.42$; recipient: $M=1.28, S D=2.12$ ). However, exploratory analyses comparing expressers' expectations against the neutral baseline (i.e., 0: "neither submissive nor dominant") showed that even expressers expected their compliment-giving behavior to be perceived as somewhat strong, on average, rather than weak, $t(108)=4.92, p<.001$. Finally, an exploratory mediation analysis testing status as an alternative mediator found that differences in perceived status did not account for a significant proportion of variance in the difference between expected versus experienced positive moods (see Supplemental Materials for more details).

Mood change. To assess the extent to which giving and receiving compliments affected participants' mood, we analyzed participants' self-reported mood (linearly transformed to a 0-10 scale) in a 2 (perspective: expresser vs. recipient $) \times 2($ compliment number: one vs. three $) \times 2$ (time: before vs. after compliments) linear mixed model. Results revealed a significant main effect of perspective, $F(1,107)=12.79, p<.001, \eta^{2}{ }_{p}=.11$, a significant main effect of time, $F(1,107)=221.78, p<.001, \eta^{2}{ }_{p}=.68$, and a significant perspective $\times$ time interaction, $F(1,107)$ $=6.60, p=.012, \eta^{2} p=.058$. Neither the main effect of compliment number nor any other interactions were statistically significant, $p s>.11$. As predicted, expressing compliments made 
the expressers feel significantly more positive (before: $M=6.29, S D=1.78$; after: $M=8.29, S D$ $\left.=1.51 ; F(1,107)=173.94, p<.001, \eta^{2} p=.62\right)$. Receiving compliments also made the recipients feel significantly more positive (before: $M=5.75, S D=2.06$; after: $M=7.29, S D=1.78$;

$\left.F(1,107)=109.10, p<.001, \eta^{2} p=.46\right)$. The significant interaction indicates that the increase in positive mood was significantly larger for recipients than for expressers. This result is inconsistent with results reported by Klein et al. (2021), who found that those asked to compliment a stranger on a character trait felt more positive after giving their compliment than the recipients did. We discuss this result in more detail in the General Discussion.

\section{Discussion}

As in Experiment 1, people underestimated how positive their compliments would make recipients feel, regardless of whether they were passing along one or three compliments, and even though they had known their recipient for an average of more than 13 years. Mediational analyses indicated that expressers' tendency to underestimate how competent their compliments would seem to their recipients, and to a lesser extent how warm they would seem, was significantly related to their tendency to underestimate the recipients' positive mood after reading their compliment. In contrast, alternate mediation models found no statistical evidence that expressers' miscalibrated expectations stemmed from either differences in evaluations of either surprise or relative status. This overall pattern of results suggests that focusing on concerns about how one is conveying a compliment—its "happy phrasing," to use Twain's term — instead of focusing on the meaning behind one's compliment — the warmth conveyed by one's phrasing - may exacerbate expressers' misunderstandings of their recipient's reactions. This then predicts that shifting expressers' attention to focus more intently on the warmth conveyed by their compliments should lead to more calibrated expectations of the recipient's 
reaction. We designed Experiment 3 to test this hypothesis by manipulating expressers' attention to either the competence or the warmth of their compliments and then measuring how they expected their recipients to react to their compliments.

\section{Experiment 3: Shifting Attention to Calibrate Expectations}

We asked one person in a pair — the expresser - to write three compliments to the other person - the recipient. Before anticipating how the recipient would feel after reading the compliments, some expressers were directed to focus on the warmth conveyed by their compliments (warmth-focused), others on the competence conveyed by their compliments (competence-focused), and others received no direction (unfocused). We predicted that those directed to focus on the warmth conveyed by their compliments would expect their recipients to react more positively than those directed to focus on competence, thereby becoming more calibrated in their expectations of their recipients' reactions because they are evaluating their compliments by focusing on similar attributes as the recipients themselves (Eyal \& Epley, 2010). If expressers are naturally focused first and foremost on the competence-related attributes of their compliments, then directing their attention to only competence-related aspects should not significantly alter their expectations compared to a condition where they evaluate both attributes without any further instruction to focus on one attribute or the other.

\section{Method}

Participants. We conducted this experiment in the same public park, using the same recruiting method, as in Experiment 1. We targeted a sample of 50 pairs in each condition, for a total of 300 participants. Our final sample included 49 pairs in the warmth-focused condition, 52 pairs in the competence-focused condition, and 49 pairs in the unfocused condition $\left(M_{a g e}=\right.$

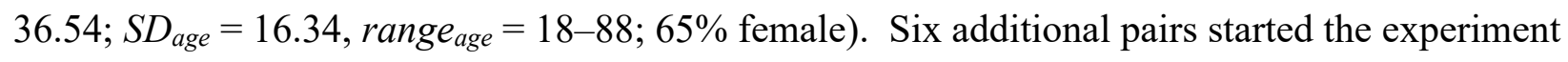


but were excluded from analyses because they left the park before finishing ( 3 pairs, 1 in each condition), lacked English proficiency (1 in the competence-focused condition), accidentally failed to read the compliments ( 1 in the warmth-focused condition), or indicated misunderstanding of the scales upon completion ( 1 in the competence-focused condition).

Procedure. Experiment 3 employed a 3 (focus: warmth-focused, competence-focused, unfocused) $\times 2$ (perspective: expresser, recipient) between-participants design. Participant pairs were randomly assigned to one of the focus conditions, and participants within each pair were assigned to be the expresser or the recipient. The procedure was similar to the compliment condition of Experiment 1 except for two changes. First, after writing three compliments and before predicting how their recipient would feel, the expressers were presented with the compliments they just wrote and were either provided with an instruction that manipulated the focus of their evaluation (warmth-focused or competence-focused conditions) or given no special instruction (unfocused condition). Specifically, we instructed participants in the warmth-focused condition to, "think about the degree to which your messages are warm and sincere, paying close attention to the overall impressions you meant to convey in your compliments." We instructed participants in the competence-focused condition to, "think about the degree to which your messages are articulate and well-written, paying close attention to the exact words you chose to include in each of your sentences."

Second, we adjusted the order and phrasing of the survey items to strengthen the evaluative focus manipulation. In the warmth-focused condition, expressers first answered a one-item question that asked them to evaluate the warmth expressed by their compliments ("How warm and sincere would you rate the compliments you wrote to be?"). In the competence-focused condition, expressers first answered a one-item question that asked them to 
evaluate the competence of their compliments ("How articulate and well-written would you rate the compliments you wrote to be?"). Participants in both conditions then predicted their recipient's positive mood and feeling of awkwardness. In the unfocused condition, expressers evaluated both the warmth and the competence of their compliments (order counterbalanced across pairs) before predicting their recipients' positive mood and awkwardness, but with no explicit request to consider one attribute or the other. Finally, similar to Experiment 1, expressers finished their task by reporting their current relationship quality with the recipient, their compliment frequency, and demographic information (gender and age).

Although our primary interest was the expressers' expectations, we also adjusted the recipients' item order and phrasing. After first reporting their moods, the recipients evaluated either warmth or competence in the warmth-focused or competence-focused conditions, respectively, or answered both in the unfocused condition (order counterbalanced).

\section{Results}

Positive mood. To test our hypotheses that directing expressers' focus to the warmth of their compliments, but not competence, can create more calibrated expectations of recipients' reactions, we analyzed the data in a 3 (condition: warmth-focused, competence-focused, unfocused) $\times 2$ (perspective: expresser, recipient) linear mixed model with participant pairs as random effects. Results revealed a significant effect of perspective, $F(1,147)=48.00, p<.001$, $\eta^{2}{ }_{p}=.25$, indicating that expressers tended to underestimate how positive their recipients felt after receiving their compliments. ${ }^{7}$ Most relevant to the current experiment, we also found a significant main effect of condition, $F(2,147)=4.80, p=.010, \eta^{2}{ }_{p}=.061$, qualified by a

\footnotetext{
${ }^{7}$ We preregistered analyses using t-tests and ANOVAs on difference scores but later realized that a linear mixed model was a better statistical approach and hence report the better analysis. Both approaches yield the same conclusions.
} 
marginally significant interaction between perspective and condition, $F(2,147)=3.00, p=.053$, $\eta_{p}^{2}=.039$. Although compliment expressers significantly underestimated how positive their recipient would feel across all three conditions (warmth-focused: $M s=8.50$ vs. 8.93 ; competence-focused: $M s=7.71$ vs. 8.62 ; unfocused: $M s=7.82$ vs. 8.95 ), simple effects tests showed that their expectations were relatively more calibrated in the warmth-focused condition $\left(F(1,48)=7.14, p=.01, \eta^{2}{ }_{p}=.028\right)$ than those in the competence-focused condition $(F(1,51)=$ $\left.15.58, p<.001, \eta^{2}{ }_{p}=.12\right)$ or the unfocused condition $\left(F(1,48)=27.33, p<.001, \eta^{2}=.17\right)$.

Also as predicted, expressers' expectations differed significantly across experimental conditions, $F(2,147)=6.47, p=.002, \eta_{p}^{2}=.081$, with participants in the warmth-focused condition expecting their recipient to feel more positive than those in the competence-focused $(F(1,147)=$ $11.14, p=.001)$ or unfocused conditions $(F(1,147)=8.13, p=.005)$. Recipients' positive mood, in contrast, did not vary significantly across conditions, $F(2,147)=1.42, p=.25, \eta^{2}{ }_{p}=.019$. These results are shown in Figure 5(A).

(A)

$\square$ Expresser $\square$ Recipient

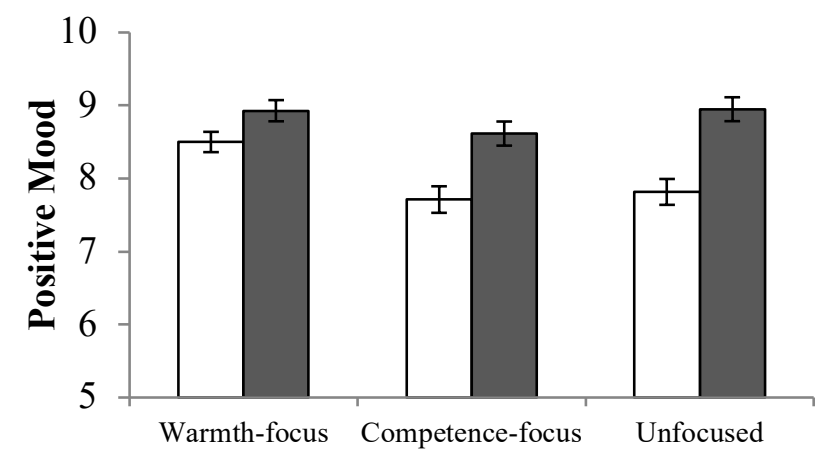

(B)

$\square$ Expresser $\square$ Recipient

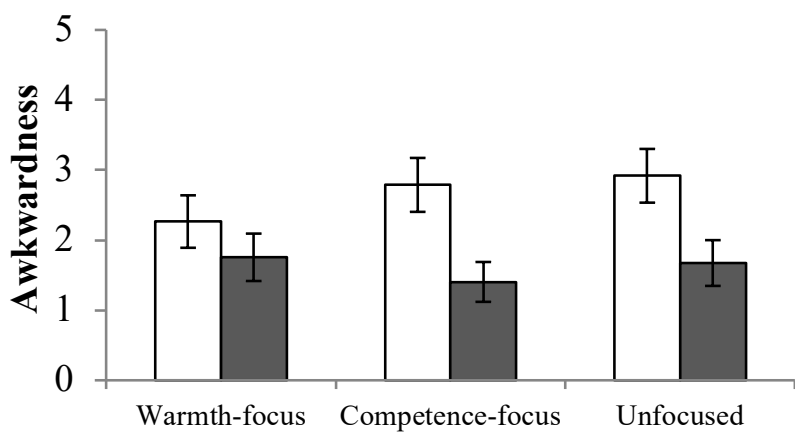

Figure 5. Participants' expected and actual positive mood (Panel A) and awkwardness (Panel B) in the warmth-focused, competence-focused, and unfocused conditions in Experiment 2. Error bars reflect \pm 1 standard errors. 
Awkwardness. A similar 3 (condition: warmth-focused, competence-focused, or unfocused) $\times 2$ (perspective: expresser, recipient) linear mixed model on feelings of awkwardness revealed a main effect of perspective, $F(1,147)=16.79, p<.001, \eta^{2}{ }_{p}=.10$, a nonsignificant main effect of condition, $F(2,147)=.29, p=.75$, and a nonsignificant interaction, $F(2,147)=1.12, p=.33$. Expressers in the warmth-focused condition did not significantly overestimate how awkward their recipients would feel $(F(1,48)=1.59, p=.21)$, whereas expressers in both the competence-focused and the unfocused conditions did (competencefocused: $M s=2.79$ vs. $1.40 ; F(1,51)=8.95, p=.004, \eta^{2}{ }_{p}=.065 ;$ unfocused: $M s=2.92$ vs. 1.67 ; $\left.F(1,48)=7.51, p=.009, \eta^{2} p=.0 .50\right)$. These results are shown in Figure 5(B).

Warmth and competence. As in Experiments 1 and 2, we examined how expressers and recipients might have systematically evaluated the same compliments differently. We only analyzed responses in the unfocused condition given that they evaluated both attributes of the same compliments. A 2 (attribute: warmth vs. competence) $\times 2$ (perspective: expresser vs. recipient) linear mixed model on the expressers' and recipients' evaluations of the compliments again showed a significant main effect for attribute, $F(1,48)=71.95, p<.001, \eta^{2}{ }_{p}=.60$, and a significant main effect of perspective, $F(1,48)=66.98, p<.001, \eta^{2}{ }_{p}=.58$, qualified by a significant interaction, $F(1,48)=45.71, p<.001, \eta^{2}{ }^{2}=.49$. Expressers underestimated recipients evaluations of competence $\left(F(1,48)=77.26, p<.001, \eta^{2} p=.62\right)$ significantly more than their evaluations of warmth $\left(F(1,48)=24.00, p<.001, \eta_{p}^{2}=.33\right)$. Replicating previous results, expressers judged the competence of their compliments significantly less favorably than recipients, suggesting that expressers were overly concerned about not getting the words "just right" or being articulate enough compared to the recipients' very positive evaluations. 
Compliment frequency. Finally, consistent with other surveys, participants again reported giving compliments significantly less often than they thought they should $(M=-.89, S D$ $=1.30), t(299)=-11.83, p<.001, d=.68$ (see Supplemental Materials).

\section{Discussion}

Experiment 3 replicated the primary results from Experiments 1 and 2, and also provides direct causal evidence that a perspective gap in evaluations of the competence versus warmth conveyed by compliments could at least partly explain expressers' miscalibrated expectations of recipients' reactions, such that aligning the perspectives could calibrate expressers' expectations. Specifically, shifting expressers' attention to focus on the warmth conveyed by their compliments made expressers' expectations more calibrated, and significantly more positive, compared to expressers who focused on the competence conveyed by their compliments or evaluated both dimensions. These results, along with other recent research (Boothby \& Bohns, 2021; Kumar \& Epley, 2018), suggest that an undue focus on competency, relative to warmth, may contribute to a broader tendency for people to underestimate the positive impact that their prosocial actions will have on others.

Although shifting expressers' attention in Experiment 3 to focus on the warmth-related dimensions of their compliments increased the calibration of their expectations, it did not fully eliminate their tendency to underestimate how positive their recipient would feel entirely. This occurs presumably because expressers also underestimate how warm their recipients will perceive compliments to be.

\section{Experiment 4: Updating Expectations to Change Intentions?}

Taken together, five experiments (Experiments 1, 2, 3, S1a, and S1b) provide consistent evidence that people systematically misunderstand the overall positive impact of compliments on 
recipients. We believe expressers' miscalibrated expectations are important because they may create a misplaced psychological barrier to expressing compliments more often in daily life. Prior research has documented somewhat related interpersonal misunderstandings, speculating about their importance but rarely testing these implications directly (e.g., Epley \& Schroeder, 2014; Flynn \& Lake, 2008; Kumar \& Epley, 2018; Sandstrom \& Dunn, 2014). Experimentally testing the consequences of mistaken expectations would therefore provide a meaningful advance from prior research and reveal how such miscalibration creates undue reluctance to express compliments in daily life.

As a first step, we investigated how people's expectations of recipients' reactions were related to their interest in expressing compliments to others. If expectations about a recipient's reaction at least partly guide people's interest in expressing compliments, then they should be more interested in giving a compliment when they expect the recipient to respond more favorably. Identifying the link between expectations and intentions is critical for establishing the plausibility of our broader hypothesis that miscalibrated expectations about others' reactions could lead people to deliver fewer compliments than might be optimal in their daily lives. We summarize two initial tests of these hypotheses here in the main text, and provide full details in the Supplemental Materials.

In Experiment S2, we asked online participants to generate compliments for five different people in their lives, to predict how positive and awkward each recipient would feel and how warm and competent that recipient would perceive the compliment to be, and then to indicate how interested they were in delivering each compliment to its intended recipient. As predicted, potential expressers' expectations of how positive and how awkward a given compliment would make their recipient feel were significantly correlated with their reported interest in expressing 
that compliment, and expected positive mood was a significantly stronger predictor of expressers' interest than was expected awkwardness. In addition, expressers' expectations of how warm and how competent a compliment would be perceived were again correlated with expectations of the recipient's positive mood and awkwardness, which were in turn positively correlated with their interest in sharing their compliments with recipients.

To test the extent to which these expectations might guide people's choices of which compliments to share with others, we conducted Experiment S3 in which we recruited acquainted pairs in the same public park described in Experiment 1. We asked those randomly assigned to be expressers to generate three compliments about the other person, to predict how this recipient would react to each compliment, and then to choose only one compliment to actually share. As predicted, participants expected that the compliment they chose to share $(M=$ 7.89; $S D=1.42$ ) would make their recipient feel significantly more positive than the compliments they did not choose to share $(M=7.08 ; S D=1.48), F(1,52)=23.83, p<.001, \eta^{2}{ }_{p}=$ .31 , but they expected similar levels of awkwardness $(p=.26)$.

Taken together, Experiments S2 and S3 suggest that people's expectations of how positive their compliments would make the recipients feel at least partly guided their interest in expressing them. If people systematically underestimate how positive their kind words will make others feel, then this could create a misplaced barrier to expressing compliments more often in daily life. This predicts that reducing this psychological barrier by calibrating people's expectations should increase their willingness to express compliments to their potential recipients.

We tested this hypothesis by attempting to manipulate people's expectations of a recipient's reaction to a compliment in two different ways. As a first attempt in Experiment S4 
(see Supplemental Materials for full details), we informed some compliment expressers that people were prone to underestimating the positive impact of compliments on receivers, and then measured the number of compliments they generated and shared with a recipient. We compared the number of compliments expressers shared in this informed condition against the number of compliments expressers shared in a separate control condition in which expressers received no information about people's tendency to underestimate the positive impact of compliments. This experiment tested whether learning about our experimental results changed the number of compliments expressers would share. Consistent with our hypothesis, expressers who were informed that people tended to underestimate the positive impact of their compliments shared marginally more compliments than those who were not informed $(M \mathrm{~s}=5.64$ and $4.77, S D \mathrm{~s}=$ 2.82 and 2.51), Mann-Whitney $U=1496, p=.08, d=0.33$. As in Experiment 2, both expressers and recipients reported feeling more positive after either expressing or receiving their compliments, although the increase in positive mood was again larger for recipients.

Given that directly informing people about experimental results had only a relatively small effect on people's expectations, we utilized a design similar to Experiment 3 in which we directed participants' attention to focus on either warmth or competence to test how manipulating attention would affect their interest in expressing compliments. If underestimating recipients' positive reaction to a compliment creates a barrier to expressing them more often, then participants in Experiment 4 who focus on the warmth conveyed by their compliments should be more interested in expressing a compliment than those who are focused on its competence.

\section{Method}


Participants. We targeted a sample of 100 participants in each of the two experimental conditions and recruited from the same participant pool as in Experiment 2. A total of 208 participants - 102 in the warmth-focused condition and 106 in the competence-focused condition-completed this experiment $\left(M_{\text {age }}=24.71, S D_{\text {age }}=6.73\right.$, range $_{\text {age }}=18-54 ; 72 \%$ female).

Procedure. Due to the COVID-19 pandemic, we conducted this experiment remotely by sending a study link to participants. Upon opening the study link, participants read the compliment-writing instruction which prompted them to write down one compliment they could give to someone in their life who did not currently live in the same household. We encouraged participants to write a compliment that they could deliver using existing channels of communication. Participants then identified a potential compliment recipient and described their relationship type and length. The relationships people identified included friendship $(N=135)$, family $(N=41)$, romantic relationship $(N=15)$, married/engaged couples $(N=7)$, professional relationship $(N=9)$, and followership $(N=1)$. Expressers reported knowing their recipient for an average of 8.87 years $(S D=9.28)$. Participants then wrote down one compliment they could give to this recipient, and reported their current mood on the same positive/negative scale used in the preceding experiments.

Participants randomly assigned to the warmth-focused condition then saw a page titled, "How warm and sincere is your compliment?", whereas those randomly assigned to the competence-focused condition saw a page titled, "How articulate and well-written is your compliment?". The first paragraph indicated that participants had an opportunity to actually deliver the compliment they had just written.

Participants in the warmth-focused condition then read the following paragraph: 
"When deciding whether or not to express a compliment, it is important to consider the spirit of compliment-giving: at its core, giving compliments is a matter of sharing warm, sincere, and friendly thoughts to another person in your life, so that they know how positively you feel about them. Therefore, when deciding whether or not to express your compliment, "[display the compliment here]", please focus on the extent to which your compliment was intended to be warm, sincere, and friendly. How warm was your compliment intended to be?"

In contrast, participants in the competence-focused condition read the following:

"When deciding whether or not to express a compliment, it is important to consider the spirit of compliment-giving: finding just the right words to articulate your thoughts about another person in your life, so that they know precisely how you feel. Therefore, when deciding whether or not to express your compliment, "[display the compliment here]”, please focus on the extent to which you were able to get the words just right, sounding clear, intelligent, and articulate. How competently were you able to express your thoughts through your compliment?

As part of this manipulation, participants then rated either the warmth or the competence of their compliments (depending on their assigned condition) on the same item as in Experiment 3.

On the next page, participants answered, "How interested are you in actually sending this exact compliment, "[compliment]", to [recipient] right now?", with the actual compliment and recipient name inserted using their own responses from an earlier part of the survey. The response scale ranged from 0 (not at all interested) to 10 (extremely interested).

On the next page, participants learned that they had a 2-minute window in which they could deliver the compliment that they wrote, if they would like to, using whatever channels of communication they normally used for interacting with their recipient. We disabled the advance 
button on this page for two minutes and provided a text template that included the recipient's name, the compliment, and a brief sentence describing the research study that they could directly copy and send (or modify before sending, if they chose to). On the next page, participants indicated whether or not they actually sent their compliment just now ("Yes, I did" or "No, I did not"). To encourage honesty, the instruction assured participants that their response would not influence their payment or their standing in our participant pool. If participants indicated having sent their compliment, then we asked them to indicate how they sent it in an open-ended text box. If participants reported that they did not send it, then we asked them to explain why they did not send their compliment. Finally, participants recalled what they were asked to focus on when deciding whether or not to send their compliment in an open-ended question (i.e., the manipulation check), reported their demographic information, and were debriefed.

\section{Results and Discussion}

We first confirmed that compliments in the warmth-focused and the competence-focused conditions were of comparable length $(p=.41)$ and required a similar amount of time for the expressers to write $(p=.49)^{8}$.

As predicted, participants in the warmth-focused condition reported being significantly more interested in expressing their compliments $(M=6.05, S D=2.93)$ than participants in the competence-focused condition $(M=4.71, S D=3.01), t(206)=3.26, p=.001, d=.45$. Consistent with our prediction, focusing on how "warm, sincere, and friendly" their compliment

\footnotetext{
${ }^{8}$ The $p$ values are calculated with all compliments. However, a few expressers wrote considerably longer compliments or spent far more time than normal on the compliment-writing page (e.g., one expresser proceeded after 10 hours with a compliment of 9 words), so in another set of analyses, we excluded outliers that were three standard deviations above the means in respective conditions and confirmed that compliments in the warmthfocused and competence-focused conditions were comparable in both word counts $(M \mathrm{~s}=25.88$ and 23.21 words, $S D \mathrm{~s}=28.16$ and 17.22 , respectively; $t(202)=0.35, p=.72)$ and writing duration $(M \mathrm{~s}=109.90$ and $121.14 \mathrm{~seconds}$, $S D \mathrm{~s}=64.08$ and 71.24 , respectively; $t(180)=-1.12, p=.27)$.
} 
was led expressers to be more interested in expressing it compared to focusing on how "clear, intelligent, and articulate" the compliment was.

Because we asked participants to evaluate the warmth or competence of their compliment to help them focus on the respective constructs, we also conducted linear regression analysis to examine whether such evaluations were related to their interest in expressing a compliment. As expected, expectations of the warmth and competence conveyed by their compliments were related to their interest in expressing their compliment (warmth: $B=.53, S E=.18, t=2.92, p$ $=.004$; competence: $B=.86, S E=.10, t=8.20, p<.001)$. Consistent with results in Experiment 3, participants in the competence-focused condition evaluated the competence of their compliments significantly more critically $(M=5.74, S D=2.19)$ than those evaluating the warmth of their compliments in the warmth-focused condition $(M=8.34, S D=1.54), t(206)=9.88, p$ $<.001, d=1.38$.

Despite having generated compliments that could be easily shared in the moment, participants did not seem especially interested in sharing their compliment during the experiment as only $49.5 \%$ of participants reported actually sending their compliment in the 2-minute window we provided. Specifically, $53.9 \%$ of participants in the warmth-focused condition (55 out of 102), compared to $45.3 \%$ in the competence-focused condition (48 out of 106), reported sending their compliments. The direction of this difference was consistent with our prediction, but was statistically nonsignificant, $\chi^{2}=1.23, p=.27, w=.12$.

To better understand why our experimental manipulation created a sizeable effect on participants' interest in expressing their compliment but a weaker effect on the percentage of participants who actually shared their compliment in this procedure, we conducted an exploratory analysis to investigate the relationship between these two variables. A logistic 
regression analysis on people's compliment-giving behavior $(0=$ did not send; $1=$ sent $)$ revealed a statistically significant relationship between reported interest in expressing a compliment and actually expressing the compliment, $b=0.44, z=6.76, p<.001$. However, interest accounted for only $22.4 \%$ of the variance in people's actual behavior $\left(\mathrm{McFadden} R^{2}=.22\right)$, indicating that whether people sent a compliment or not in the window of opportunity provided in our experiment was largely driven by additional factors.

Analyzing people's verbal explanations revealed that the most common reported reason for withholding compliments was timing. Specifically, $58.6 \%$ of those who did not send their compliments ( $N=58$ out of 99 responses) mentioned that they either knew the other person would be preoccupied at that moment, or they felt that sending compliments would seem "random" and "out of the blue" and/or preferred to deliver the compliment face-to-face or when a more suitable occasion naturally arose. Other participants explained that they felt "weird", “embarrassed", or "uncomfortable" about sending their compliments or were afraid the other person would react negatively (15.2\%); they preferred to rewrite the compliments using more effective language (8.1\%); they found compliment-giving too "emotional" or uncharacteristic of their normal interactions $(5.0 \%)$; they felt lazy or tired $(5.0 \%)$; they lacked a channel to reach the other person during the study (4.0\%); or they thought the compliments were already known to the intended recipient (4.0\%). We offered participants a two-minute window in which to send their compliment because it enabled us to easily measure behavior, but it may not have been optimal for measuring actual compliment-giving in daily life.

Finally, a pre-registered analysis on only those participants who passed what turned out to be a very restrictive manipulation check (99 out of our 208 participants provided warmthrelated or competence-related keywords in the open-ended recall question) yielded larger main 
effects, suggesting that a stronger experimental manipulation would have yielded larger behavioral effects. Specifically, the effect of condition on reported interest in expressing a compliment was considerably larger in this restricted sample than it was in the entire sample, $t(97)=4.04, p<.001, d=.81(d=.45$ in the full sample $)$; moreover, $56.9 \%$ of those in the warmth-focused condition reported having sent their compliment compared to $41.7 \%$ in the competence-focused condition (compared to $53.9 \%$ vs. $45.3 \%$ in the full sample), $\chi^{2}=1.72, p=$ .19 .

These results suggest that underestimating recipients' positive evaluations of a compliment, and hence their positive reaction to it, could create a barrier to expressing compliments in daily life. Reducing this psychological barrier by encouraging people to focus on the warmth conveyed by their compliment therefore increased their interest in expressing a compliment that they could express to another person. Future research will have to assess whether offering a longer time period for expressing a compliment, or measuring actual behavior using a different study design, would increase the correspondence between reported interest and actual expressions of compliments. Future research can also assess whether participants' apparent concern about getting the timing or occasion "just right" for their compliment is warranted, or if it represents another manifestation of expressers underestimating how competent their compliment-giving will be perceived by recipients. Note that our experiments measured expressers' expectations of how competently their compliment would be evaluated by recipients - the "happy phrasing of a compliment" to use Twain's words from our opening quote-but did not measure how competently their delivery of the compliment would be evaluated —-what Twain referred to as a compliment's "happy delivery." Our research suggests 
that that expressers' concerns about the competent delivery of a compliment could also be miscalibrated.

\section{General Discussion}

"The deepest principle in human nature is the craving to be appreciated."

-William James (1896/1920)

People care a great deal about how they are evaluated by others, leaving people feeling good when they find out that they are appreciated by others (Leary \& Baumeister, 2000). Unlike William James, who may well have recognized the full power of feeling appreciated, our data suggest that people may instead think more like Mark Twain, believing the happy phrasing and receipt of a compliment to be somewhat rare. In fact, our experiments suggest a reliable tendency to underestimate how positive signs of appreciation-in this case expressing compliments — will make recipients feel. Across multiple experiments (Experiments 1-4), pairs of friends, family, and romantic couples consistently underestimated how positive, and overestimated how awkward, their recipients would feel upon receiving their compliments. Our experiments indicate that these miscalibrated expectations stem from expressers' overly critical view of how competent, and to a lesser extent how warm, their compliments would be viewed by the recipients, creating a perspective gap between those who receive a compliment and those who are anticipating its consequences. We also found that third-party observers, like the expressers, also underestimated the positive impact of compliments on a recipient (Supplemental Experiments S1a and S1b). These miscalibrated expectations matter in daily life because they are likely to guide people's interest in expressing versus withholding genuine compliments that come to their mind (Supplemental Experiments S2 and S3). Undervaluing compliments could 
therefore create a psychological barrier to expressing them more often in daily life, such that more accurately recognizing a recipients' positive response could increase interest in expressing compliments more often (Experiments S4 and 4).

Prior research has primarily framed the motivation to express compliments through a lens of self-presentation and ingratiation (e.g., Jones, 1964; Seiter, 2007; Vonk, 2001). Although people may sometimes attempt to manipulate others through flattery and false praise, people also care deeply about others' well-being. We assume that at least some compliments are prosocially motivated efforts to make another person feel good by expressing authentic positive thoughts. However, our theorizing does not preclude the possibility that giving compliments can also make the expressers feel good. In fact, as with other prosocial acts that make the actors feel good (Dunn et al., 2014; Curry et al., 2018), participants giving compliments in our Experiments 1 and S4 also felt more positive after doing so than they did moments before (see also Boothby \& Bohns, 2021). Recent research focusing on exchanging compliments between strangers even suggests that giving compliments might make people feel better than receiving compliments (Klein et al., 2021). Two of our experiments, in contrast, found that receiving compliments enhanced positive mood more than giving compliments, possibly because our compliments were shared within established relationships and hence might have been more meaningful and powerful to the recipients. Regardless of its exact magnitude, existing research consistently indicates that giving compliments enhances a person's own well-being. This effect could come from expressers' conscious focus on positive thoughts about a relationship partner (Emmons \& McCullough, 2003; Fredrickson, Cohn, Coffey, Pek, \& Finkel, 2008; Lyubomirsky \& Layous, 2013), but it could also come from expecting to achieve the goal of making a recipient feel positive by giving a compliment (Dunn et al., 2014). A misplaced reluctance to share kind 
thoughts with others could leave people being less prosocial than would be optimal for their own well-being.

Although our experiments provide strong converging evidence across multiple experiments, our compliment-giving procedure is constrained in one important way: expressers were prompted to write compliments in one sitting, whereas everyday life affords repeated interactions with recipients in which compliments are generated and shared spontaneously. This feature of our procedure may raise two concerns. First, expressers may have been forced to generate low-quality or insincere compliments in our experiments. However, expressers in Experiment 3 who could write as many compliments as they wished wrote a median number of five to another person, suggesting that the request to write multiple compliments was not likely forcing expressers to write more compliments than they would have been able to write otherwise. Second, prompted compliments may lead to different attributional inferences than spontaneously generated compliments, either among expressers or recipients. A prompted comment might be expected to be perceived as less sincere by expressers, and/or might actually be perceived as less sincere by recipients. We note, however, that our pattern of results replicated consistently across contexts where the number of compliments generated was fixed versus freely chosen by the expresser, and recipients' evaluations were also nearly at the ceiling of the positive affect measure across all experiments, suggesting that they fully appreciated the compliments. Although we doubt that the prompted nature of our experimental procedures is meaningfully influencing evaluations of sincerity among either expressers or recipients, future research should test the robustness of our results in more spontaneous compliment-giving contexts. 


\section{From miscalibration to misconnection}

Connecting with others in a positive way tends to feel good, such that relatively prosocial actions can sometimes leave people feeling even happier than relatively selfish ones (Dunn et al., 2008). Performing prosocial actions intended to benefit others feels good at least partly to the extent that those actions actually achieve the actor's intended goal. An effective act of kindness that leaves another person better off makes the giver feel happier, while an ineffective act of kindness that leaves another person feeling indifferent also makes the giver feel less positive. Given how easy a genuine compliment is to generate, and how positive it can make recipients feel when expressed, it is somewhat surprising that our participants consistently reported giving fewer compliments either than they would like to give or than they should give. We believe a tendency to systematically underestimate how positively others will respond to a compliment can help to explain this surprising sentiment. If a person believes a genuine compliment will leave another person feeling relatively indifferent, or feeling somewhat awkward, then they might be somewhat reluctant to give it. That these expectations tend to be systematically miscalibrated suggests that people's expectations may create a mistaken barrier to prosocial actions.

The tendency for people to underestimate the perceived competence of their kind words to a greater extent than perceived warmth also suggests that underestimating the positive impact of prosocial actions is likely to be a somewhat widespread phenomenon. Prosocial actions lead recipients to feel good at least partly because they convey warmth from another person. If prosocial actors instead tend to be relatively more focused on how competently they are executing the action, then a very wide range of prosocial acts are likely to leave the average recipient feeling better than the prosocial actors expect. Indeed, prior research has documented a similar tendency to underestimate how positively others will respond to relatively elaborate and 
deliberate expressions of gratitude (Kumar \& Epley, 2018), and to honesty (Levine \& Cohen, 2018). We would hypothesize similar miscalibrated expectations in reactions to expressions of social support, random acts of kindness, deep and meaningful conversation, or any other act where the primary impact on recipients is an expression of positive intentions or liking (i.e., warmth). Miscalibrated expectations could create barriers to a wide variety of behaviors that would otherwise strengthen social bonds and enhance well-being. Importantly, our hypotheses do not suggest that people simply misunderstand the impact that their own actions have on others. We would not expect systematically miscalibrated expectations about how others will respond to actions defined by their competence, such as a boss's reaction to a report, a diner's reaction to a prepared meal, an audience's reaction to a presentation, or a reader's reaction to a journal article.

In addition to underestimating the positive impact of prosocial acts, our mechanism also predicts the inverse: underestimating the negative impact of antisocial acts on others. Behaviors defined by their lack of warmth, such as deception, insults, or rejection, could have created a more negative impact on recipients than antisocial actors expect. Although direct support for this hypothesis is lacking, recent research has suggested that people underestimate the severity of other people's pain from social exclusion when not actively experiencing such pain for themselves (Nordgren et al., 2011). Other experiments indicate that those on the receiving end of a social action are sensitive to an actor's intention, such that recipients report feeling more pain when they were intentionally harmed than unintentionally harmed (Gray \& Wegner, 2008). Investigating actors' expectations in these antisocial contexts can provide important theoretical and practical implications. One particularly timely context for such investigation is social media, where antisocial behaviors including hate speech, Internet trolling, and public shaming are both 
common and impactful (Ronson, 2015). One possible explanation for the frequency of antisocial behaviors online is that the distance between actors and recipients of an antisocial action makes actors especially likely to underestimate the harm they inflict on recipients.

\section{Moderating Miscalibration and Compliment-Giving}

We have documented that underestimating how positive a compliment will make a recipient feel could serve as meaningful psychological barrier for giving compliments more often and provided evidence for one explanation of miscalibrated expectations based on differences in perceptions of competence and warmth (Abele \& Wojciszke, 2007; Bruk et al., 2018; Fiske et al., 2007; Wojciszke et al., 1998). Of course, our research does not identify or address all of the factors that could moderate the magnitude of miscalibration or the frequency of complimentgiving in everyday life.

One potentially surprising feature of our experimental results is that miscalibrated expectations emerged among people in long-term relationships, suggesting that interpersonal misunderstanding is not simply something that occurs between strangers (Boothby \& Bohns, 2021). Even in long-term relationships, people do not seem to fully appreciate the positive impact that their kind words can have on their relationship partners. We believe this misunderstanding is likely to be maintained over time because miscalibrated expectations about social interactions can keep people from engaging in the very behaviors that would otherwise calibrate their expectations (Epley \& Schroeder, 2014). If a person believes that compliments are largely met with indifference by others, then they may be reluctant to give them and hence never find out that their expectations could be wrong. Simply gaining experience by giving more compliments and observing people's reactions may create more calibrated expectations and perhaps encourage more positive expressions as well. Those who give compliments more 
frequently, whether due to their personality, occupation, or random assignment to experimental condition, should also be more calibrated in predicting others' reactions. Miscalibrated expectations could be perpetuated by a lack of experience that could otherwise calibrate their expectations.

The frequency of compliment-giving also varies across cultures. Americans, for instance, reportedly give more compliments than both English and non-English speakers in other countries (Fujimura-Wilson, 2014). Although our participant samples were diverse on some dimensions (such as age and ethnicity), we did not test our hypotheses around the world, and so we cannot test how our effects may have been moderated by nationality or geography. We suggest that cross-cultural differences in the expression of compliments may stem from differences in expressers' expectations rather than in recipients' experiences of compliments. In contrast to individualistic cultures, the heightened focus on hierarchy and relationship status in collectivistic cultures may focus expressers' attention even more intensely on how they are conveying a compliment rather than on the prosocial intent and warmth behind the compliment itself. Cultural norms can be guided not only by people's actual experience, but also by their beliefs and expectations about others, whether calibrated or miscalibrated (Miller \& Prentice, 1994). Investigating the extent to which variance in prosocial norms across cultures is driven by differences in expectations or actual experiences is a critical topic for future research.

Although we have suggested that undue attention to competence-related aspects of one's compliment can lead expressers to underestimate how positive their compliments will make recipients feel, compliments do vary in the warmth they convey. For example, some compliments are sincere and genuine while others are insincere and merely flattering. Because we were primarily interested in understanding barriers to expressing genuine compliments, we 
did not investigate either expectations about or experiences of disingenuous compliments. Jones (1964) noted that those trying to enhance their own image in the eyes of others by using selfpresentational tactics, such as flattery, face a dilemma: ingratiators want to use tactics that make them liked by others, but the most extreme tactics may also be the most likely to be detected as insincere. Someone aiming to flatter another person therefore needs to pass along their compliments without being detected as insincere. Existing empirical evidence, however, suggests that this may create a dilemma primarily in the minds of the ingratiators themselves. Empirical evidence suggests that recipients may be relatively insensitive to ulterior motives and may happily accept obvious flattery (Chan \& Sengupta, 2010; Fogg \& Nass, 1996; Vonk, 2002; Westphal \& Stern, 2007). Research also suggests that people are fairly poor at detecting lies from speech alone (Bond \& Depaulo, 2006), suggesting that people may have difficulty recognizing the difference between sincere and insincere compliments. And yet, because people are aware of their own intentions behind a compliment, they may expect those intentions will be more transparent to observers than they actually are (Gilovich, Savitsky, \& Medvec, 1998). People may be reluctant to flatter others with insincere compliments because they overestimate the likelihood that their insincerity will be detected. At this point, however, we know of no research that examines how accurately compliment recipients discount for an expressers' actual sincerity, or how accurately expressers can anticipate discounting in their recipients.

Finally, people may be reluctant to express compliments more often in daily life out of a concern that expressing more compliments to another person may also make them seem less authentic, or may make their compliments less effective. One compliment may be taken as authentic and make the recipient feel good, but a second might feel a little less good, a third even less good, and so on. This concern seems plausible and somewhat grounded in psychological 
reality - for instance, as additional exposures to certain types of stimuli can lead to adaptation, thereby diminishing the intensity of emotional reactions (Frederick \& Loewenstein, 1999; Wilson \& Gilbert, 2008). However, recent evidence has suggested that people may underestimate how much they enjoy repeated experiences (O’Brien, 2019), thus overestimating the speed with which they will adapt to repeated exposures of the same stimulus. Adaptation also arises in response to repeated exposures of the same stimuli over time, so recipients might be expected to adapt to the very same compliment over time, but it is not clear that receiving different compliments would lead to adaptation given that each would be conveying a uniquely positive message. Finally, adaptation rates vary across stimuli. Concerns about belonging seem to be a basic need that may need to be repeatedly satisfied, meaning that people may not tire of hearing repeated affirmations about themselves or reassurances that they are valued and liked by others (Leary \& Baumeister, 2000). In a series of experiments following a similar procedure to Experiment 1 (Zhao \& Epley, 2020), one person within a pair of close friends, romantic partners, or family members was randomly assigned to be the expresser and the other person to be the recipient. Expressers wrote five compliments for their recipient, who was then shown one compliment each day over the course of the week. People who did not know the details of the compliments expected recipients to feel progressively less positive over the course of the week. By contrast, recipients actually felt equally positive over the course of the week, showing no evidence of adaptation, and generally feeling more positive than both expressers and third-party observers expected. Considerably more research is needed to understand how expectations of adaptation may also create a reluctance to be routinely prosocial.

Giving compliments in relationships makes both expressers and recipients feel more positive than they expect to feel, suggesting that people's relationships might be a little better off 
if they were less reluctant to pass along kind thoughts when they had them. Surely there is some balance to be found between giving compliments too rarely and giving them too frequently. Our experiments do not identify that critical tipping point. They also do not suggest that people should spend all of their time sharing every single kind thought they have with others. Instead, our experiments simply suggest that the optimal frequency of compliment-giving is likely to be at least a little more often than people may currently be giving. 


\section{REFERENCES}

Abele, A. E., \& Wojciszke, B. (2007). Agency and communion from the perspective of self versus others. Journal of Personality and Social Psychology, 93(5), 751-763.

Baumeister, R. F., \& Leary, M. R. (1995). The need to belong: Desire for interpersonal attachments as a fundamental human motivation. Psychological Bulletin, 117(3), 497-529.

Becker, G. S. (1993). The economic way of looking at behavior. Journal of Political Economy, 101(3), 385-409.

Behrens, T. E., Hunt, L. T., \& Rushworth, M. F. (2009). The computation of social behavior. Science, 324(5931), 1160-1164.

Bentham, J. (1825). The Rationale of Reward. London: John and H. L. Hunt.

Bond, C. F., \& DePaulo, B. M. (2006). Accuracy of deception judgments. Personality and Social Psychology Review, 10(3), 214-234.

Boothby, E. J., \& Bohns, V. K. (2021). Why a Simple Act of Kindness Is Not as Simple as It Seems: Underestimating the Positive Impact of Our Compliments on Others. Personality and Social Psychology Bulletin.

Boothby, E., Cooney, G., Sandstrom, G., \& Clark, M. (2018). The liking gap in conversation: Do people like us more than we think? Psychological Science, 29(11), 1742-1756.

Bruk, A., Scholl, S. G., Bless, H., \& Gilbert, E. (2018). Beautiful mess effect: Self-other differences in evaluation of showing vulnerability. Journal of Personality and Social Psychology, 115(2), 192-205.

Chan, E., \& Sengupta, J. (2010). Insincere flattery actually works: A dual attitudes perspective. Journal of Marketing Research, 47(1), 122-133. 
Chapman, G. (1995). The five love languages: How to express heartfelt commitment to your mate. Chicago, IL: Northfield Publishing.

Chaudhry, S. J, \& Loewenstein, G. (2019). Thanking, apologizing, bragging, and blaming: Responsibility exchange theory and the currency of communication. Psychological Review.

Cooney, G., Gilbert, D. T., \& Wilson, T. D. (2014). The unforeseen costs of extraordinary experience. Psychological Science, 25(12), 2259-2265.

Crocker, J., Canevello, A., \& Brown, A. A. (2017). Social motivation: Costs and benefits of selfishness and otherishness. Annual Review of Psychology, 68(1), 299-325.

Curry, O. S., Rowland, L. A., Van Lissa, C. J., Zlotowitz, S., McAlaney, J., \& Whitehouse, H. (2018). Happy to help? A systematic review and meta-analysis of the effects of performing acts of kindness on the well-being of the actor. Journal of Experimental Social Psychology, $76,320-329$.

Decker, J. H., Otto, A. R., Daw, N. D., \& Hartley, C. A. (2016). From creatures of habit to goaldirected learners: Tracking the developmental emergence of model-based reinforcement learning. Psychological Science, 27(6), 848-858.

DeNeve, K. M., \& Cooper, H. (1998). The happy personality: A meta-analysis of 137 personality traits and subjective well-being. Psychological bulletin, 124(2), 197.

Diener, E., \& Diener, M. (1995). Cross-cultural correlates of life satisfaction and self-esteem. Journal of Personality and Social Psychology, 68, 653- 663.

Dunn, E. W., Aknin, L. B., \& Norton, M. I. (2008). Spending money on others promotes happiness. Science, 319(5870), 1687-1688. 
Dunn, E. W., Aknin, L. B., \& Norton, M. I. (2014). Prosocial spending and happiness: Using money to benefit others pays off. Current Directions in Psychological Science, 23(1), 4147.

Emmons, R. A., \& McCullough, M. E. (2003). Counting blessings versus burdens: An experimental investigation of gratitude and subjective well-being in daily life. Journal of Personality and Social Psychology, 84(2), 377-389.

Epley, N., Keysar, B., Van Boven, L., \& Gilovich, T. (2004). Perspective taking as egocentric anchoring and adjustment. Journal of Personality and Social Psychology, 87(3): 327-39.

Epley, N., \& Schroeder, J. (2014). Mistakenly seeking solitude. Journal of Experimental Psychology: General, 143(5), 1980-1999.

Eyal, T., \& Epley, N. (2010). How to seem telepathic: Enabling mind reading by matching construal. Psychological Science, 21(5), 700-705.

Fea, C. J., \& Brannon, L. A. (2006). Self-objectification and compliment type: Effects on negative mood. Body Image, 3, 183-188.

Fiske, S. T., Cuddy, A. J. C., \& Glick, P. (2007). Universal dimensions of social cognition: warmth and competence. Trends in Cognitive Sciences, 11(2), 77-83.

Flynn, F. J., \& Lake, V. K. B. (2008). If you need help, just ask: Underestimating compliance with direct requests for help. Journal of Personality and Social Psychology, 95(1), 128-143.

Fogg, B. J., \& Nass, C. (1997). Silicon Sycophants: The effect of computers that flatter. International Journal of Human-Computer Studies, 46(5), 551-561.

Fredrickson, B. L., Cohn, M. A., Coffey, K. A., Pek, J., \& Finkel, S. M. (2008). Open hearts build lives: Positive emotions, induced through loving-kindness meditation, build 
consequential personal resources. Journal of Personality and Social Psychology, 95(5), $1045-1062$.

Frederick, S., \& Loewenstein, G. (1999). Hedonic adaptation. In D. Kahneman \& E. Diener (Eds.), Well-being: The foundations of hedonic psychology (pp. 302-329). New York, NY: Russell Sage.

Fujimura-Wilson, K. (2014). A cross-cultural study of compliments and compliment responses in conversation. English and English and American Literature, 49, 19-36.

Gilovich, T., Savitsky, K., \& Medvec, V. H. (1998). The illusion of transparency: Biased assessments of others' ability to read one's emotional states. Journal of Personality and Social Psychology, 75(2), 332-346.

Goldin-Meadow, S., So, W. C., Özyürek, A., \& Mylander, C. (2008). The natural order of events: How speakers of different languages represent events nonverbally. Proceedings of the National Academy of Sciences, 105(27), 9163-9168.

Gordon, R. A. (1996). Impact of ingratiation on judgments and evaluations: A meta-analytic investigation. Journal of Personality and Social Psychology, 71(1), 54-70.

Gray, K., \& Wegner, D. M. (2008). The sting of intentional pain. Psychological Science, 19(12), $1260-1262$.

Izuma, K., Saito, D. N., \& Sadato, N. (2008). Processing of social and monetary rewards in the human striatum. Neuron, 58(2), 284-294.

James, W. (1896/1920). Familiar letters of William James - II. The Atlantic Monthly. Retrieved from https://www.theatlantic.com/past/docs/issues/96may/nitrous/jamii.htm.

Jones, E. E. (1964). Ingratiation. New York: Appleton-Century-Crofts. 
Jones, S. C. (1973). Self- and interpersonal evaluations: Esteem theories versus consistency theories. Psychological Bulletin, 79(3), 185-199.

Kahneman, D., Wakker, P. P., \& Sarin, R. (1997). Back to Bentham? Explorations of experienced utility. The Quarterly Journal of Economics, 112(2), 375-406.

Knapp, M. L., Hopper, R., \& Bell, R. A. (1984). Compliments: A descriptive taxonomy. Journal of Communication, 34, 12-31.

Kumar, A., \& Epley, N. (2018). Undervaluing gratitude : Expressers misunderstand the consequences of showing appreciation. Psychological Science, 29(9), 1423-1435.

Kwang, T., \& Swann, W. B. (2010). Do people embrace praise even when they feel unworthy? a review of critical tests of self-enhancement versus self-verification. Personality and Social Psychology Review, 14(3), 263-280.

Lambert, N. M., Clark, M. S., Durtschi, J., Fincham, F. D., \& Graham, S. M. (2010). Benefits of expressing gratitude. Psychological Science, 21(4), 574-580.

Leary, M. R. (2007). Motivational and emotional aspects of the self. Annual Review of Psychology, 58, 317-344.

Leary, M. R., \& Baumeister, R. F. (2000). The nature and function of self-esteem: Sociometer theory. Advances in Experimental Social Psychology, 32, 1-62.

Levine, E. E., \& Cohen, T. R. (2018). You can handle the truth: Mispredicting the consequences of honest communication. Journal of Experimental Psychology: General, 147(9), 14001429.

Lyubomirsky, S., \& Layous, K. (2013). How do simple positive activities increase well-being? Current Directions in Psychological Science, 22(1), 57-62. 
Marigold, D. C., Holmes, J. G., \& Ross, M. (2007). More than words: Reframing compliments from romantic partners fosters security in low self-esteem individuals. Journal of Personality and Social Psychology, 92(2), 232-248.

Miller, D. T., \& Prentice, D. A. (1994). Collective errors and errors about the collective. Personality and Social Psychology Bulletin, 20(5), 541-550.

Nordgren, L. F., Banas, K., \& Macdonald, G. (2011). Empathy gaps for social pain: Why people underestimate the pain of social suffering. Journal of Personality and Social Psychology, $100(1), 120-128$.

O’ Brien, E. (2019). Enjoy it again: Repeat experiences are less repetitive than people think. Journal of Personality and Social Psychology, 116(4), 519-540.

Ong, D. C., Goodman, N. D., \& Zaki, J. (2018). Happier than thou? A self-enhancement bias in emotion attribution. Emotion, 18(1), 116-126.

Pinker, S. (2007). The stuff of thought: Language as a window into human nature. New York, NY: Penguin.

Read, D. (2007). Experienced utility: Utility theory from Jeremy Bentham to Daniel Kahneman. Thinking and Reasoning, 13 (1), 45-61.

Ronson, J. (2015). So you've been publicly shamed. New York, NY: Penguin.

Sandstrom, G. M., \& Dunn, E. W. (2014). Social interactions and well-being: The surprising power of weak ties. Personality and Social Psychology Bulletin, 40(7), 910-922.

Seiter, J. S. (2007). Ingratiation and gratuity: The effect of complimenting customers on tipping behavior in restaurants. Journal of Applied Social Psychology, 37(3), 478-485. 
Slobin, D. I. (1996). From "thought and language" to "thinking for speaking". In J. J. Gumperz \& S. C. Levinson (Eds.), Rethinking linguistic relativity: Studies in the social and cultural foundations of language, No. 17 (pp. 70-96). New York: Cambridge University Press.

Swann, W. B., Griffin, J. J., Predmore, S. C., \& Gaines, B. (1987). The cognitive-affective crossfire: When self-consistency confronts self-enhancement. Journal of Personality and Social Psychology, 52(5), 881-889.

Twain, M. (1966). Mark Twain's satires and burlesques. Berkeley, CA: University of California Press.

Rees-Miller, J. (2011). Compliments revisited: Contemporary compliments and gender. Journal of Pragmatics, 43, 2673-2688.

Van Boven, L., Loewenstein, G., Dunning, D., \& Nordgren, L. F. (2013). Changing places: A dual judgment model of empathy gaps in emotional perspective taking. Advances in Experimental Social Psychology, 48, 117-171.

Vonk, R. (2001). Aversive self-presentations. In R. M. Kowalski (Ed.), Behaving badly: Aversive interpersonal behaviors (pp. 79-155). Washington, DC: American Psychological Association.

Vonk, R. (2002). Self-serving interpretations of flattery: Why ingratiation works. Journal of Personality and Social Psychology, 82(4), 515-526.

Westphal, J. D., \& Stern, I. (2007). Flattery will get you everywhere (Especially if you are a male caucasian): How ingratiation, boardroom behavior, and demographic minority status affect additional board appointments at U.S. companies. Academy of Management Journal, $50(2), 267-288$. 
Wilson, T. D., \& Gilbert, D. T. (2005). Affective forecasting: Knowing what to want. Psychological Science, 14(3), 131-134.

Wilson, T. D., \& Gilbert, D. T. (2008). Explaining away: A model of affective adaptation. Perspectives on Psychological Science, 3, 370- 386.

Wojciszke, B., Bazinska, R., \& Jaworski, M. (1998). On the dominance of moral categories in impression formation. Personality and Social Psychology Bulletin, 24(12): 1251-1263.

Zhao, X. \& Epley, N. (2020). Kind words do not become tired words: Undervaluing the positive impact of frequent compliments. Self and Identity, 20(1), 25-46, DOI:

$10.1080 / 15298868.2020 .1761438$ 